\title{
High density and ligand affinity confer ultrasensitive signal detection by a guanylyl cyclase chemoreceptor
}

\author{
Magdalena Pichlo, ${ }^{1,2}$ Stefanie Bungert-Plümke, ${ }^{2,3}$ Ingo Weyand, ${ }^{2,3}$ Reinhard Seifert, ${ }^{1,2}$ Wolfgang Bönigk, \\ Timo Strünker, ${ }^{1,2}$ Nachiket Dilip Kashikar, ${ }^{1,2,4}$ Normann Goodwin, ${ }^{1,2,5}$ Astrid Müller, ${ }^{1}$ Heinz G. Körschen, ${ }^{1}$ Ursel Collienne, \\ Elisabeth Kremmer, ${ }^{10}$ and U. Benjamin Kaupp ${ }^{1,2}$ \\ Center of Advanced European Studies and Research, 53175 Bonn, Germany \\ ${ }^{2}$ Marine Biological Laboratory, Woods Hole, MA 02543 \\ ${ }^{3}$ Institute of Complex Systems (ICS-4), Forschungszentrum Jülich, 52425 Jülich, Germany \\ ${ }^{4}$ Sussex Neuroscience, School of Life Sciences, University of Sussex, Brighton BN1 9QG, England, UK \\ ${ }^{5}$ Babraham Institute, Cambridge CB22 3AT, England, UK \\ 6III. Physikalisches Institut, Universität Göttingen, 37077 Göttingen, Germany \\ ${ }^{7}$ Leibniz-Institut für Molekulare Pharmakologie, 13125 Berlin, Germany \\ ${ }^{8}$ Plant Biochemistry, Ruhr University Bochum. 44801 Bochum, Germany \\ ${ }^{9}$ Department of Functional Neuroanatomy, Institute of Anatomy and Cell Biology, Heidelberg University, 69120 Heidelberg, Germany \\ ${ }^{10}$ Institut für Molekulare Immunologie, Helmholtz-Zentrum München, 81377 München, Germany
} Patric Pelzer, ${ }^{2,9}$ Qui Van, ${ }^{6}$ Jörg Enderlein, ${ }^{6}$ Clementine Klemm, ${ }^{7}$ Eberhard Krause, ${ }^{7}$ Christian Trötschel, ${ }^{8}$ Ansgar Poetsch, ${ }^{8}$

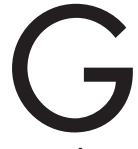
vanylyl cyclases (GCs), which synthesize the messenger cyclic guanosine $3^{\prime}, 5^{\prime}$-monophosphate, control several sensory functions, such as phototransduction, chemosensation, and thermosensation, in many species from worms to mammals. The GC chemoreceptor in sea urchin sperm can decode chemoattractant concentrations with single-molecule sensitivity. The molecular and cellular underpinnings of such ultrasensitivity are not known for any eukaryotic chemoreceptor. In this paper, we show that an exquisitely high density of $3 \times 10^{5} \mathrm{GC}$ chemoreceptors and subnanomolar ligand affinity provide a high ligand-capture efficacy and render sperm perfect absorbers. The GC activity is terminated within $150 \mathrm{~ms}$ by dephosphorylation steps of the receptor, which provides a means for precise control of the GC lifetime and which reduces "molecule noise." Compared with other ultrasensitive sensory systems, the 10-fold signal amplification by the GC receptor is surprisingly low. The hallmarks of this signaling mechanism provide a blueprint for chemical sensing in small compartments, such as olfactory cilia, insect antennae, or even synaptic boutons.

\section{Introduction}

Some cells are endowed with exquisite sensitivity: they can sense environmental cues at the physical limit. Photoreceptors respond to single photons (Pugh and Lamb, 2000; Yau and Hardie, 2009), sperm can register single molecules of chemoattractants (Kaupp et al., 2003; Strünker et al., 2006; Bönigk et al., 2009),

M. Pichlo, S. Bungert-Plümke, and I. Weyand contributed equally to this paper. Correspondence to U. Benjamin Kaupp: u.b.kaupp@caesar.de

Abbreviations used in this paper: $A M$, acetoxymethylester; ASW, artificial sea

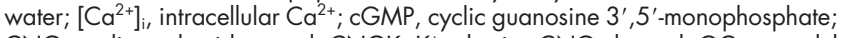
CNG, cyclic nucleotide gated; CNGK, $\mathrm{K}^{+}$-selective CNG channel; GC, guanylyl cyclase; IBMX, 3-isobutyl-1-methylxanthine; KHD, kinase homology domain; LC, liquid chromatography; $\mathrm{MS}$, mass spectrometry; $\mathrm{pH}_{\mathrm{i}}$, intracellular $\mathrm{pH}$; $\mathrm{PSAQ}$, protein standard for absolute quantification; Q-TOF, quadrupole time of flight; SRM, selected reaction monitoring; TMA, trimethylamine; $V_{m}$, membrane voltage. olfactory neurons can generate single-molecule responses (Bhandawat et al., 2010) and register subpicomolar pheromone concentrations (Leinders-Zufall et al., 2000; Zufall and Munger, 2010), and Caenorhabditis elegans can track temperature changes as small as $0.1^{\circ} \mathrm{C}$ (Hedgecock and Russell, 1975; Ramot et al., 2008). Several of these sensory feats involve synthesis of cyclic guanosine $3^{\prime}, 5^{\prime}$-monophosphate (cGMP) by receptor guanylyl cyclases (GCs). They serve from worms to mice as chemoreceptors for semiochemicals such as small peptides (Leinders-Zufall

(c) 2014 Pichlo et al. This article is distributed under the terms of an Attribution-NoncommercialShare Alike-No Mirror Sites license for the first six months after the publication date (see http://www.rupress.org/terms). After six months it is available under a Creative Commons License (Attribution-Noncommercial-Share Alike 3.0 Unported license, as described at http:// creativecommons.org/licenses/by-nc-sa/3.0//. 
Table 1. Density of GC in A. punctulata sperm

\begin{tabular}{lcccc}
\hline Parameters & \multicolumn{3}{c}{ Densitometry } & MS (PSAQ) \\
\cline { 2 - 4 } & $\boldsymbol{\alpha}$-Macroglobulin & Phosphorylase b & Recombinant GC \\
\hline GC molecules/cell & $2.53 \pm 1.22 \times 10^{5}(16)$ & $2.96 \pm 1.65 \times 10^{5}(13)$ & $3.38 \pm 2.79 \times 10^{5}(16)$ & $1.79 \pm 0.33 \times 10^{5}(6)$ \\
GC density/micrometer squared & $7,200 \pm 3,500$ & $8,500 \pm 4,700$ & $9,700 \pm 8,000$ & $5,100 \pm 900$ \\
Occupancy of the flagellar surface & $16 \pm 8 \%$ & $19 \pm 10 \%$ & $21 \pm 18 \%$ & $11 \pm 2 \%$ \\
\hline
\end{tabular}

Means \pm SD. Numbers in parentheses indicate number of animals; each animal has been analyzed at least in duplicates. The density has been calculated assuming a surface area of $35 \mathrm{\mu m}^{2}$. The occupancy of the flagellar surface has been calculated assuming a globular structure of the GC with a diameter of $5.3 \mathrm{~nm}$.

et al., 2007), carbon dioxide (Sun et al., 2009; Hallem et al., 2011), carbon disulfides (Munger et al., 2010), and extracellular pH (Murayama et al., 2013). GCs are also key to pathogen defense in plants (Irving et al., 2012). Despite their prominent role in chemosensory signaling, the mechanisms have not been established by which chemoreceptor GCs encode spatiotemporal stimulus patterns. In fact, the molecular and cellular underpinnings of single-molecule sensitivity are not known for any eukaryotic chemosensory cell.

Sperm of the sea urchin Arbacia punctulata provide a unique system to reveal the cellular makings underlying singlemolecule detection in quantitative terms. For sensing a chemical gradient, sperm perform a variety of computational operations (Alvarez et al., 2014). Sperm temporally sample single chemoattractant molecules impinging on their flagella and integrate the binding events to generate a summed $\mathrm{Ca}^{2+}$ response (Kashikar et al., 2012; Kaupp, 2012). The signaling pathway involves a chemoreceptor GC (Singh et al., 1988) and three different ion channels (Gauss et al., 1998; Strünker et al., 2006) that generate the voltage and $\mathrm{Ca}^{2+}$ response. Whereas the signaling mechanisms downstream of the receptor have been elucidated, it is not known how the chemoreceptor encodes single binding events by rapid sampling $(0.5 \mathrm{~s})$ and maintains its sensitivity over a wide dynamic range.

Here, we identify four novel features of the GC receptor that provide insight into ultrasensitive signaling: (1) an exquisitely high GC density, (2) a high ligand affinity combined with a wide dynamic range spanning several orders of magnitude of chemoattractant, (3) rapid inactivation by multiple dephosphorylations of the receptor, and (4) a surprisingly low signal amplification that, however, is sufficient to produce a single-molecule response in sperm. The high density, wide dynamic range and rapid receptor inactivation allow sperm to maintain a high sensitivity during rapid, repetitive probing of chemoattractant concentrations at sampling rates $\leq 1 \mathrm{~Hz}$.

\section{Results}

The receptor density is extraordinarily high In a landmark paper, Berg and Purcell (1977) derived from first physical principles the precision by which cells can measure the concentration of a chemical ligand. A crucial determinant of sensitivity is the number of absorbing chemoreceptors on the cell surface. For bacteria operating at micromolar concentrations of chemoattractant, $\sim 15,000$ receptors/cell are required to track down a chemical gradient precisely (Sourjik and Wingreen, 2012). However, sperm operate in the picomolar regime of concentrations when only a few molecules hit the cell surface (Kaupp et al., 2003; Kashikar et al., 2012). To explain the precision by which sperm can sample molecules, we determined the copy number of GC/sperm cell by two independent methods. First, we used quantitative mass spectrometry (MS) in combination with stable-isotope dilution. As a protein standard for absolute quantification (PSAQ; Brun et al., 2007), full-length GC labeled with ${ }^{13} \mathrm{C} /{ }^{15} \mathrm{~N}$ during heterologous expression in Sf21 cells was used. The purified PSAQ-GC was analyzed for the fraction of isotope incorporation. The absolute amount of protein was determined by quantitative amino acid analysis. A. punctulata sperm $\left(5 \times 10^{7}\right.$ cells) were dissolved in SDS sample buffer, and then, the PSAQ-GC was added. After in-gel digestion, the peptides were eluted from the gel and analyzed by MS. We obtained a value of $179,020 \pm 32,550 \mathrm{GC}$ molecules/sperm cell (mean $\pm \mathrm{SD}$; $n=33,6$ animals). Second, we measured the GC density by densitometric analysis of Coomassie-stained sperm proteins separated by SDS-PAGE (Fig. S1). The intensity of the GC band was compared with that of two standard proteins and purified recombinant GC. The mean number of GC molecules per cell determined by densitometry was $295,760 \pm 18,870$ (mean \pm SD of mean values from the three standards; Table 1). The copy numbers derived from these independent approaches agree reasonably well. Previous accounts reported $\leq 20 \times$ lower GC densities (Shimomura and Garbers, 1986; Shimomura et al., 1986; Nishigaki and Darszon, 2000). Although we do not know the reason for this discrepancy, we emphasize that the two methods consistently yield high receptor densities.

The GC is localized to the flagellum (Bönigk et al., 2009). Assuming a flagellar surface area of $35 \mu^{2}$ (length of $45 \mu \mathrm{m}$ and radius of $0.125 \mu \mathrm{m}$ ), the density ranges between 5,100 and 8,500 GC molecules/micrometer squared. Considering a diameter of $5.3 \mathrm{~nm}$ for the globular extracellular domain (molecular mass of $\sim 60 \mathrm{kD}$ ), the GC covers $11-19 \%$ of the flagellar surface. Thus, the GC rivals with rhodopsin in photoreceptors (20,000 rhodopsin molecules/micrometer squared) as one of the most densely packed membrane receptors.

Many ion channels and receptors form supramolecular complexes (signalosome) to enhance signaling efficacy (Huber et al., 1996; Tsunoda et al., 1997; Scott and Zuker, 1998). For signaling complexes to be effective, its components, e.g., the source and target of a cellular messenger, such as cGMP, must exist in equal molar quantities. Therefore, we determined the ratio between the $\mathrm{GC}$ and the $\mathrm{K}^{+}$-selective cyclic nucleotidegated (CNG) channel (CNGK; Strünker et al., 2006; Bönigk et al., 2009), the downstream target of cGMP signaling. We used 
isotope-labeled AQUA (absolute quantification) peptides for quantification of protein ratios (Gerber et al., 2003). Before tryptic digestion, the sample was spiked with three different AQUA peptides each for GC and CNGK. AQUA peptides often report lower copy numbers of proteins (Brun et al., 2007), because not all of the target peptides are quantitatively recovered during various preparation steps. For example, protein digestion may be incomplete, and digested peptides may not be fully eluted from the gel. Indeed, the recovery rate of GC peptides during the preparation was low (15-25\%). We determined a ratio of $24 \pm 5$ GC copies per CNGK ( $n=19,5$ animals). Assuming that peptide recovery was similar for the receptor and the channel, we obtained a density of $355 \mathrm{CNGK}$ molecules/micrometer, i.e., similar to the density of the CNG channel in rod photoreceptors (Haynes et al., 1986; Zimmerman and Baylor, 1986; Cook et al., 1989). This result argues that GC and CNGK do not assemble in a signalosome.

\section{Chemoattractant binding spans six orders of magnitude}

Instead of using a classical receptor-ligand binding assay, we developed a bioassay that allowed measuring ligand binding over six orders of magnitude of resact concentrations. Intact sperm were incubated with various concentrations of the chemoattractant resact. Free and sperm-bound resact was separated by centrifugation. Free resact in the supernatant was used to evoke $\mathrm{Ca}^{2+}$ signals in sperm that had been loaded with the $\mathrm{Ca}^{2+}$ indicator Fluo-4 (Kaupp et al., 2003). The free resact concentration was determined by comparing the slope of $\mathrm{Ca}^{2+}$ signals evoked by the supernatant with signals evoked by defined resact concentrations. Using this assay, a binding isotherm was determined for concentrations ranging from $1 \mathrm{pM}$ to $1 \mu \mathrm{M}$. The binding isotherm was shallow and saturates at $\sim 1 \mu \mathrm{M}$ resact (126 experiments; Fig. 1 A). A fit of the Hill equation to the binding data yielded a constant of half-maximal binding $K_{1 / 2}$ of $0.65 \pm 0.08 \mathrm{nM}$ and a Hill coefficient of $n=0.49 \pm$ 0.03 (mean \pm standard error of the regression).

Members of the GC family form homodimers or trimers (Wilson and Chinkers, 1995; Yu et al., 1999; Vaandrager, 2002; Ogawa et al., 2004). Therefore, the low Hill coefficient might reflect negative cooperativity among binding sites, i.e., the level of receptor occupancy regulates binding affinity. Alternatively, the receptor population might be composed of a mixture of receptors with a range of different $K_{1 / 2}$ values; such a mixture will give rise to shallow binding curves with anomalously low Hill coefficients. Both mechanisms predict that the binding affinity is higher when only one GC subunit in the dimer/trimer is occupied. We tested this prediction at low levels of receptor occupancy $(\leq 25 \%)$. A fit of the data with a simple binding isotherm yielded a $K_{\mathrm{d}}$ value of $90 \pm 84 \mathrm{pM}$ (24 experiments; range of 1.6-301.2 pM; Fig. 1 B). Whatever the mechanism might be, this result shows that $K_{1 / 2}$ values change with receptor occupancy, which extends the operational range and, thereby, prevents premature receptor saturation.

The receptor GC rapidly inactivates after ligand binding

Generating a single-molecule response not only requires that a single resact molecule binds and activates a receptor but also
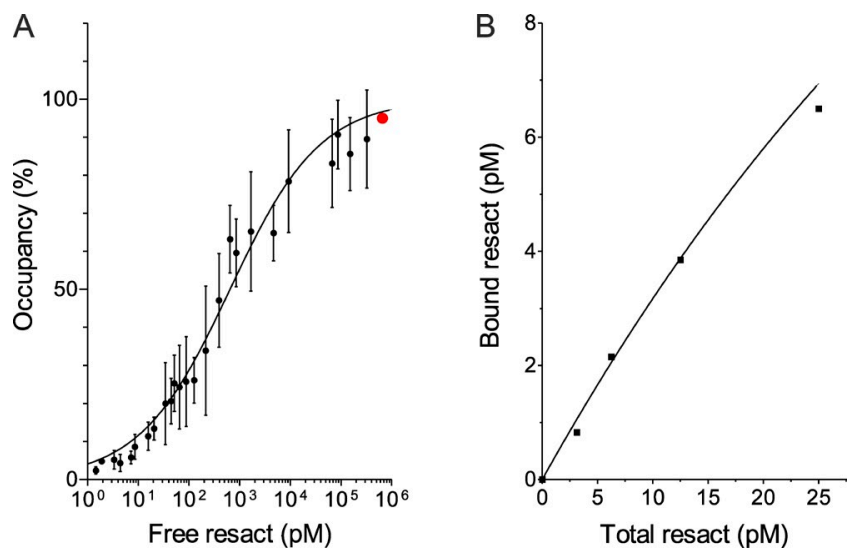

Figure 1. Ligand affinity of sperm GC. (A) Dose-response relation of resact binding. The continuous line represents a fit of the Hill equation to the data from a total of 126 experiments. Each data point represents the mean \pm $\mathrm{SD}$ of at least three experiments. The constant of half-maximal binding was $K_{1 / 2}=0.65 \pm 0.08 \mathrm{nM}$, and the Hill coefficient was $n=0.49 \pm 0.03$. The occupancy at $\sim 750 \mathrm{nM}$ resact was set to $95 \%$ (31 experiments; red dot). (B) Dose-response relation at low resact concentrations. The solid line was calculated using a simple binding model using a $K_{d}$ of $250 \mathrm{pM}$.

that activation of a single receptor generates sufficient cGMP molecules, which is $\sim 25$ cGMP molecules (Bönigk et al., 2009). Previous accounts using classical steady-state enzyme assays with broken cells or solubilized receptors reported GC activities that varied by more than four orders of magnitude between experiments (Table S1), and the signaling gain was far too small for single-molecule sensitivity. To revisit this issue, we kinetically followed GC activity by measuring cGMP synthesis in intact sperm with the quenched-flow technique (Kaupp et al., 2003). Resact stimulates a steep rise of cGMP followed by a rapid decline, reflecting synthesis and hydrolysis of cGMP, respectively (Kaupp et al., 2003). To study the rate of cGMP synthesis on its own, hydrolysis was prevented by 3-isobutyl-1methylxanthine (IBMX), a phosphodiesterase inhibitor. Under these conditions, the cGMP concentration rapidly reached a stable plateau (Fig. 2 A; Kaupp et al., 2003), showing that cGMP synthesis ceased within $\sim 0.4$ s. The cGMP synthesis might be terminated by depletion of the substrate GTP, by GC inactivation, or both. Two observations argue for GC inactivation: the cGMP increase tapers off even at low resact concentrations, and the amount of cGMP synthesized (Kaupp et al., 2003) is much less than the cellular GTP concentration ( $\gtrsim 1 \mathrm{mM})$.

From the time course of cGMP increase (Fig. 2 B), two functionally important parameters can be derived: the turnover number $T$, i.e., the number of cGMP molecules synthesized by an active $\mathrm{GC}\left(\mathrm{GC}^{*}\right)$ per second, and the rate constant of inactivation $k_{\mathrm{i}}$. Both measures set the signaling gain. The turnover number $T$ was derived according to Eqs. 1-4 (Materials and methods), assuming a bimolecular reaction between ligand and GC. The mean value of $T$ was $72.2 \pm 28.7$ cGMP molecules/ second (seven concentrations with 3-10 experiments; Fig. 2 C). The GC activity rapidly declined (Fig. 2 B) with a rate constant $k_{\mathrm{i}}$ of $6.4 \pm 2.4 \mathrm{~s}^{-1}$ (Fig. $2 \mathrm{D}$ ), corresponding to an inactivation time $\tau_{\mathrm{i}}$ of $157 \mathrm{~ms}$. Thus, during the GC* lifetime, on average, 11 cGMP molecules are produced. The turnover number is similar to that reported for GC-E and GC-F in retinal photoreceptors 

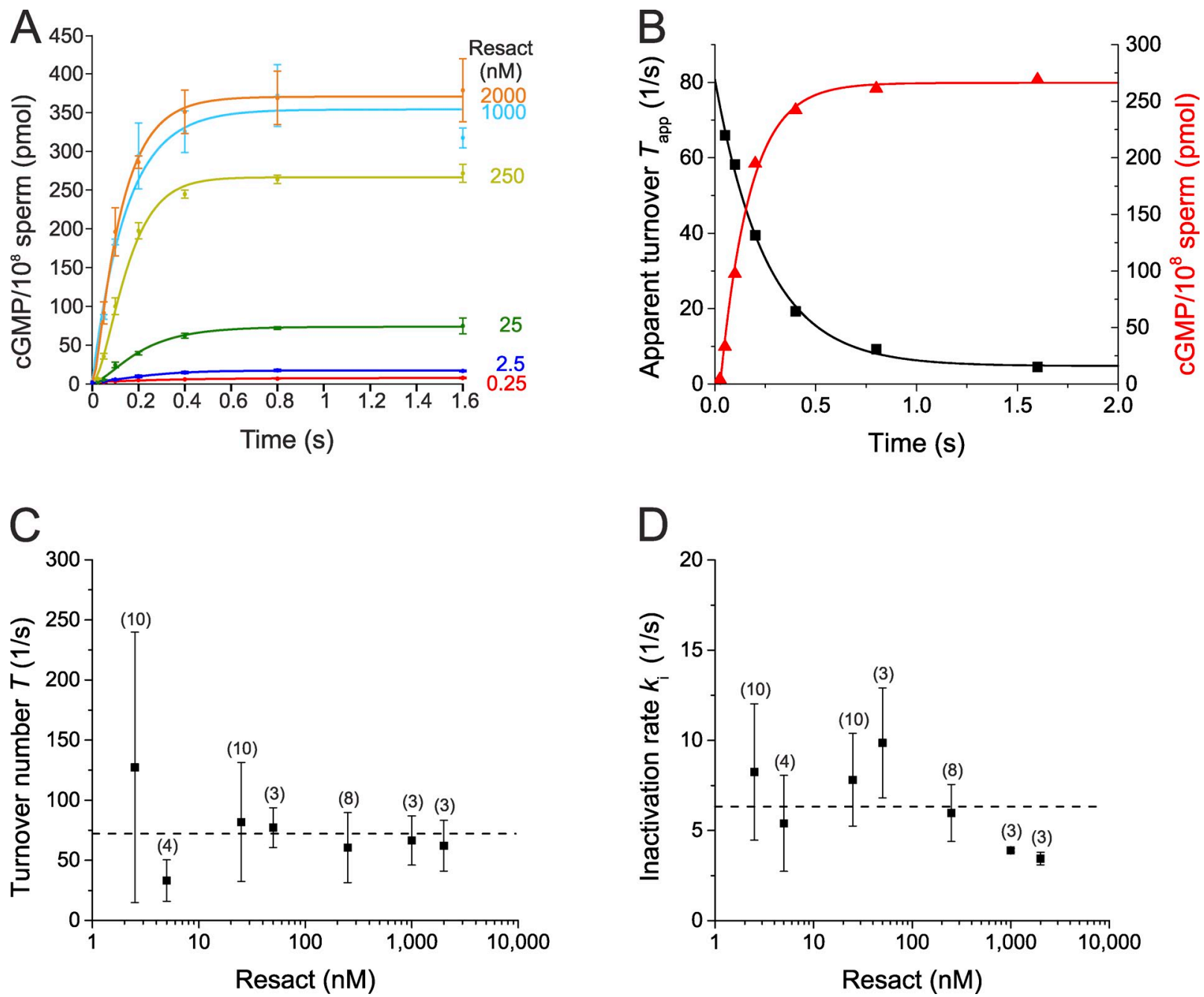

Figure 2. Turnover number and inactivation kinetics of GC. (A) Time course of cGMP production in the presence of $1 \mathrm{mM} I B M X$ at different resact concentrations. Error bars are means \pm SD from at least three experiments. (B) Time course of cGMP synthesis (red triangles) for sperm stimulated with 250 nM resact. The apparent turnover number of GC (black squares) was calculated by using Eqs. 1-3 (Materials and methods). The data shown are from a single representative experiment out of 12 from six different animals. Lines represent exponential fits. (C and D) Turnover number (C) and inactivation rate of $G C$ (D) versus resact concentration. Each data point represents the mean \pm SD. Dashed lines denote the mean turnover number and inactivation rate over all concentrations, respectively ( $T=72.2 \pm 28.7 \mathrm{cGMP}$ molecules/second; $\left.k_{\mathrm{i}}=6.4 \pm 2.4 \mathrm{~s}^{-1}\right)$. Number of experiments is given in parentheses above the data points. Turnover numbers and inactivation rates were calculated from time courses of cGMP.

(74-116 cGMP molecules/second; Peshenko et al., 2011) but many orders of magnitude larger than that determined by steadystate assays (Table S1), which grossly underestimate the turnover caused by rapid GC inactivation.

\section{Inactivation of GC is caused by dephosphorylation}

The GC is phosphorylated at rest and becomes dephosphorylated upon resact binding (Ward and Vacquier, 1983; Suzuki et al., 1984; Ward et al., 1986), suggesting that the GC inactivates by dephosphorylation. We identified by tandem MS the amino acid residues that are phosphorylated at rest and become dephosphorylated after resact stimulation. Curiously, the published sequence of the A. punctulata GC (Singh et al., 1988), the founding member of the GC family (Wedel and Garbers, 2001), lacks the canonical sequence motif of the catalytic domain. We reexamined the primary structure of the GC by cloning of cDNA from an A. punctulata testis library. The derived amino acid sequence differs from the published sequence by 203 residues in the Cterminal region that carries the catalytic domain. MS analysis identified 14 peptides of the new C-terminal region present in native GC (Fig. S2 A). We identified six phosphorylated serine residues in the unstimulated GC (S558, S562, S569, S572, S575, and S1106; Fig. S2 A and Table S2), five of which are located in the kinase homology domain (KHD). After resact stimulation, four phosphorylated residues became completely dephosphorylated: for S562, S569, and S572 in the KHD and $\mathrm{S} 1106$ in the C-terminal region, we only identified dephosphorylated peptides. For S558 and S575, we estimated that $\sim 10 \%$ and $1 \%$ of these residues remained phosphorylated, respectively (Table S3). A loss of $\leq 15$ phosphate groups has been reported (Vacquier and Moy, 1986). We do not know the reason for this discrepancy; however, we note that previous studies on other GCs revealed less than eight phosphate groups per GC (Potter and Hunter, 1998a,b; Potter, 2011). 
A
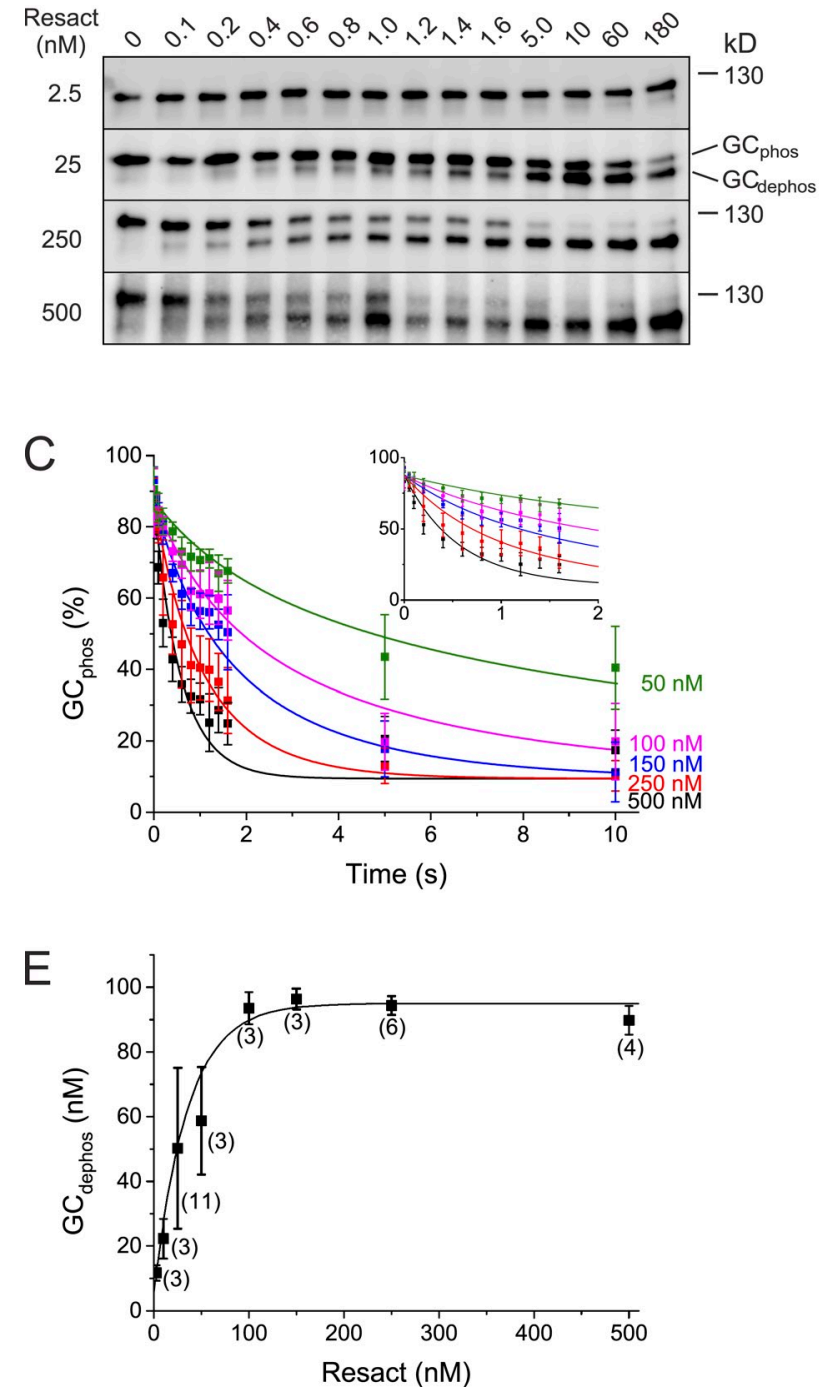
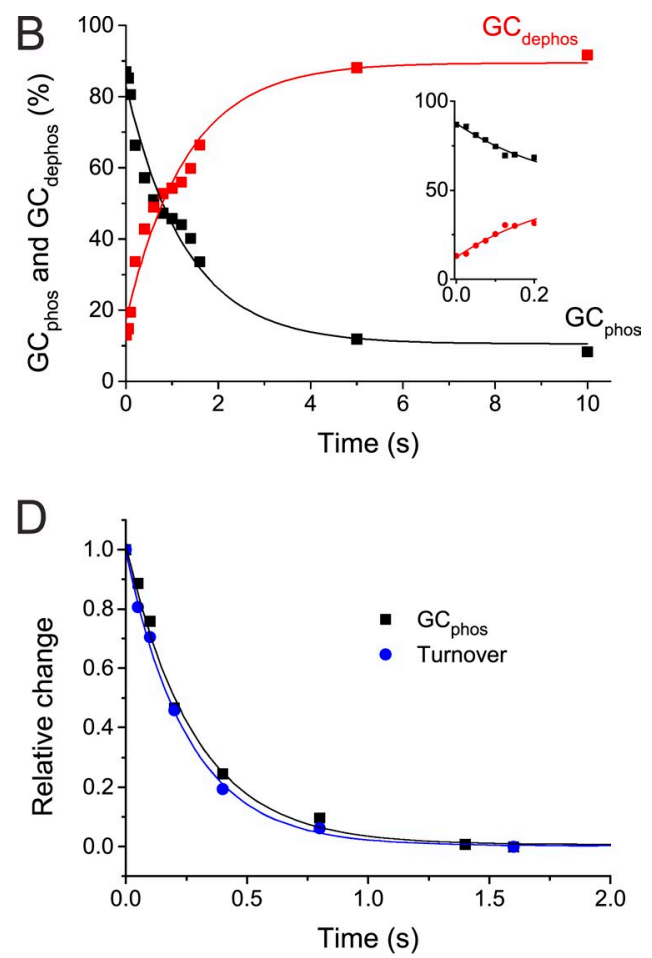

Figure 3. Kinetics of dephosphorylation. (A) Representative Western blot of GC dephosphorylation at different resact concentrations. The amount of GC was adjusted to $120 \mathrm{nM}$. Sperm were stimulated with 2.5, 25, 250, or $500 \mathrm{nM}$ resact. The time lapse in seconds after resact application is indicated above the respective lanes. The molecular mass of a protein size marker is shown on the right. (B) Fraction of dephosphorylated and phosphorylated GC versus time after stimulation with $250 \mathrm{nM}$ resact. Inset shows the dephosphorylation reaction during the first $200 \mathrm{~ms}$. Data shown are from a single representative experiment out of 12 from six different animals. Lines represent exponential fits. (C) Time course of dephosphorylation for resact concentrations from 50 to $500 \mathrm{nM}$. The time constant $\left(\tau_{\text {dephos }}=133 \mathrm{~ms}\right)$ was obtained by using a global fit that includes ligand binding and unbinding. Each data point represents the mean $\pm S D$ of at least three experiments. The inset shows the dephosphorylation reaction during the first $2 \mathrm{~s}$. (D) Comparison of the time course of relative turnover number and dephosphorylation. Both time courses were normalized according to the minimum-maximum method. The data shown are from a single representative experiment out of 12 from six different animals. $(E)$ Amount of $G C_{\text {dephos }}$ after 3 min of incubation with different resact concentrations. Total GC concentration was adjusted to $120 \mathrm{nM}$. Each data point represents the mean \pm SD. Number of experiments is given in parentheses. Lines represent exponential fits in $B, D$, and $E$.

Next, we studied whether dephosphorylation of GC could be the mechanism of inactivation. First, we compared the kinetics of inactivation and dephosphorylation. Upon stimulation, the GC undergoes a shift in electrophoretic mobility that is associated with a loss of phosphate groups on serine residues (Ward and Vacquier, 1983; Suzuki et al., 1984; Vacquier and Moy, 1986). We used the shift of $\sim 4 \mathrm{kD}$ to follow kinetically the dephosphorylation by Western blotting of protein samples from sperm that had been rapidly quenched at various times after mixing with resact (Fig. 3 A). Of note, only a single shift in electrophoretic mobility was observed, although several phosphate groups are removed. We do not know in quantitative terms the phosphorylation status of the upper and lower band. They may consist of a mixed population of GC molecules with different phosphorylation patterns. Moreover, the mobility shift might come along with the removal of a single phosphate only. In fact, a similar observation is known for the Dictyostelium discoideum cAMP receptor; it also exhibits a single mobility shift upon phosphorylation of a specific amino acid residue in a sequence of five phosphorylation steps (Klein et al., 1987; Caterina et al., 1995). We used the motility shift as an indicator for dephosphorylation by itself and refer to the unstimulated population as $\mathrm{GC}_{\text {phos }}$ and to the shifted population as $\mathrm{GC}_{\text {dephos }}$. 
The changes in $\mathrm{GC}_{\text {phos }}$ and $\mathrm{GC}_{\text {dephos }}$ species were stoichiometric and followed a similar time course (Fig. 3 B). Of note, a change in GC phosphorylation was apparent as early as $25 \mathrm{~ms}$ after stimulation. Dephosphorylation started instantaneously with no latency: linear extrapolation of the initial slope of the dephosphorylation rate intercepted with the amount of dephosphorylated GC at $t=0$ (Fig. $3 \mathrm{~B}$, inset). Thus, dephosphorylation precedes changes in membrane voltage $\left(V_{\mathrm{m}}\right)$, intracellular $\mathrm{pH}\left(\mathrm{pH}_{\mathrm{i}}\right)$, and intracellular $\mathrm{Ca}^{2+}\left(\left[\mathrm{Ca}^{2+}\right]_{\mathrm{i}}\right)$ that display latencies of several tens to hundreds of milliseconds (Kaupp et al., 2003; Strünker et al., 2006).

The inactivation rate was largely independent of ligand concentration over more than three orders of magnitude (Fig. 2 D). The invariant $k_{\mathrm{i}}$ is remarkable, considering that the GC is the most abundant protein. This result suggests that inactivation is an intrinsic property of the GC rather than the result of an extrinsic enzymatic reaction. We further analyzed the time constant $\tau_{\text {dephos }}$ of the dephosphorylation reaction. The following model described the time course of dephosphorylation:

$$
\left[\mathrm{GC}_{\text {phos }}\right]+[\mathrm{L}] \underset{k_{-1}}{\stackrel{k_{1}}{\rightleftarrows}}\left[\mathrm{GC}_{\text {phos }} \mathrm{L}\right] \stackrel{k_{2}}{\longrightarrow}\left[\mathrm{GC}_{\text {dephos }} \mathrm{L}\right] \underset{k_{-3}}{\stackrel{k_{3}}{\rightleftarrows}}\left[\mathrm{GC}_{\text {dephos }}\right]+[\mathrm{L}]
$$

wherein $\mathrm{L}$ denotes the ligand, $k_{1}$ and $k_{-1}$ denote the on and off rate constants of binding to $\mathrm{GC}_{\text {phos }}$, respectively, $k_{2}$ is the rate constant of dephosphorylation, and $k_{3}$ and $k_{-3}$ are the respective rate constants of binding to $\mathrm{GC}_{\text {dephos }}$. A global fit of the data to this model yielded a $k_{2}$ of $7.53 \pm 4.6 \mathrm{~s}^{-1}$ or a $\tau_{2}$ of $133 \mathrm{~ms}$ (Fig. $3 \mathrm{C}$ ). Thus, the mean $\tau_{\mathrm{i}}=157 \mathrm{~ms}$ and $\tau_{\text {dephos }}=133 \mathrm{~ms}$ match. This match is also evident when comparing the time course of GC inactivation and GC dephosphorylation (Fig. 3 D). Although we do not know which step in the dephosphorylation reaction reflects the mobility shift, the similar time course suggests that dephosphorylation terminates GC activity.

At low occupancy, dephosphorylation was superstoichiometric. For example, when $\leq 25 \%$ of the GC monomers were occupied, about twice as many GC molecules were dephosphorylated (Fig. 3 E). This finding suggests that the stoichiometry for the resact-to-receptor binding is $1: 2$, similar to the stoichiometry of atrial natriuretic peptide binding to GC-A (Ogawa et al., 2004). Alternatively, if the stoichiometry of resact binding were $1: 1$, this would imply that an occupied receptor could dephosphorylate an empty receptor by a trans-mechanism.

\section{Does alkaline-induced dephosphorylation terminate GC signaling?}

Resact initiates a rapid alkalinization by stimulating the activity of an $\mathrm{Na}^{+} / \mathrm{H}^{+}$exchanger (Johnson et al., 1983), and artificial alkalinization of the cytosol by weak bases causes dephosphorylation of the GC, suggesting that resact-induced alkalinization terminates GC activity via dephosphorylation (Ramarao and Garbers, 1985; Ward et al., 1986; Darszon et al., 2008). However, direct proof of this mechanism is lacking. Using the $\mathrm{pH}_{\mathrm{i}}$ indicator BCECF, we compared resact-induced changes in $\mathrm{pH}_{\mathrm{i}}$ (Fig. S3 A) with the changes produced by mixing sperm with the weak bases $\mathrm{NH}_{4} \mathrm{Cl}$ and trimethylamine (TMA; Fig. S3, B and C).
The maximal $\Delta \mathrm{pH}_{\mathrm{i}}$ of 0.2 evoked by resact was similar to the $\Delta \mathrm{pH}_{\mathrm{i}}$ evoked by mixing of sperm with $1 \mathrm{mM} \mathrm{NH} \mathrm{NH}_{4} \mathrm{Cl}$ or $3 \mathrm{mM}$ TMA (Fig. S3, B and C). However, alkalization by $1 \mathrm{mM} \mathrm{NH}_{4} \mathrm{Cl}$ or $3 \mathrm{mM}$ TMA did not cause GC dephosphorylation (Fig. 4, $\mathrm{A}$ and $\mathrm{B}$ ). Higher concentrations of $\mathrm{NH}_{4} \mathrm{Cl}$ or TMA produced a stronger alkalization (Fig. S3, B and C) and, indeed, induced a slow GC dephosphorylation that required $\geq 5$ min to become noticeable (Fig. 4, A and B). We conclude that physiological changes in $\mathrm{pH}_{\mathrm{i}}$ do not produce $\mathrm{GC}$ dephosphorylation; moreover, dephosphorylation evoked by strong, nonphysiological alkalization proceeds too slowly to account for the rapid inactivation and dephosphorylation caused by resact.

Nevertheless, we took advantage of the alkaline-induced dephosphorylation to independently test whether dephosphorylated $\mathrm{GC}$, in fact, is inactive and cannot be activated by resact. After a 15-min incubation of sperm with $122 \mathrm{mM}$ TMA, the mobility shift was complete, indicating dephosphorylation (Fig. 4 C), and the cGMP synthesis induced by $250 \mathrm{nM}$ resact was abolished (Fig. 4 D). In untreated control sperm, which contained only phosphorylated GC, $250 \mathrm{nM}$ resact induced both a substantial dephosphorylation within $1.6 \mathrm{~s}$ (Fig. $4 \mathrm{C}$, left) and a rapid cGMP increase that leveled off after $0.4 \mathrm{~s}$ (Fig. 4 D). In conclusion, dephosphorylation is the principle mechanism of receptor inactivation, and the dephosphorylated GC cannot be activated by resact.

\section{Recombinant GC is inactive}

The originally cloned GC was inactive (Singh et al., 1988), not surprising considering that the catalytic domain was lacking. We tested whether the full-length GC is active when heterologously expressed. To this end, we coexpressed the GC with a cGMP-sensitive CNG channel (Altenhofen et al., 1991; Schröder-Lang et al., 2007) in HEK293 cells to monitor the cGMP synthesis via $\mathrm{Ca}^{2+}$ influx. Immunohistochemistry on intact HEK293 cells and membrane sheets demonstrated that the GC was targeted to the plasma membrane (Fig. 5 A). However, even high resact concentrations failed to evoke $\mathrm{a} \mathrm{Ca}^{2+}$ response, whereas superfusion of cells with 8-bromo (Br)-cGMP, a membrane-permeable cGMP analogue, produced a large $\mathrm{Ca}^{2+}$ signal (Fig. 5, B and C). We next examined, whether heterologously expressed GC was properly glycosylated and phosphorylated. The apparent molecular mass of native dephosphorylated GC was larger than that of recombinant GC. Upon treatment with PNGase, the molecular mass of native GC became smaller, whereas the molecular mass of recombinant GC was largely unchanged (Fig. 5 D). After deglycosylation, the native dephosphorylated GC and the recombinant GC run almost at the same apparent molecular mass. These results show that recombinant GC is differently glycosylated and also dephosphorylated. Alterations of these posttranslational modifications may be the reason why the recombinant protein is nonfunctional (Koller et al., 1993; Müller et al., 2010).

\section{Dephosphorylation is independent of} signaling events downstream of GC GC activation by resact first evokes a rapid, transient hyperpolarization (Fig. 6 A; Babcock et al., 1992; Strünker et al., 2006) that triggers all other downstream signaling events. In the presence 

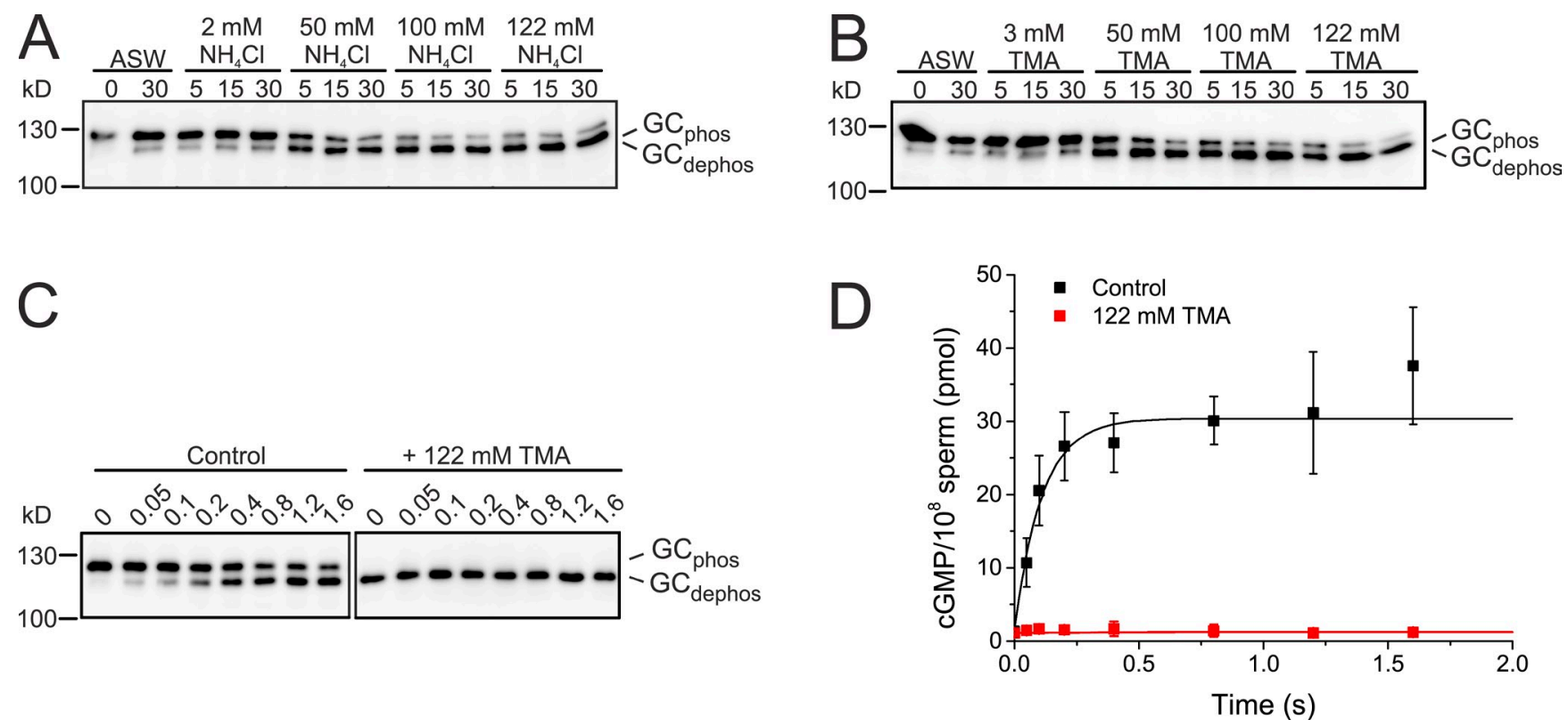

Figure 4. GC is inactivated by dephosphorylation. (A and B) Western blots showing dephosphorylation of GC induced by intracellular alkalization. $\mathrm{pH}_{\mathrm{i}}$ was elevated by different concentrations of $\mathrm{NH}_{4} \mathrm{Cl}(\mathrm{A})$ or TMA (B). The concentrations of the base and incubation times (minutes) are indicated above the respective lanes. The molecular masses of two protein size markers are shown on the left. (C) Representative Western blot of dephosphorylation by alkaline $\mathrm{pH}$. (right) First, GC was dephosphorylated by incubation of sperm with $122 \mathrm{mM}$ TMA for 15 min. Subsequently, sperm were stimulated with $250 \mathrm{nM}$ resact. The time lapse after resact stimulation (seconds) is indicated above the respective lines. The molecular masses of two protein size markers are shown on the left. The left shows control dephosphorylation after resact stimulation in the absence of TMA. (D) Time course of cGMP synthesis in the presence of $2 \mathrm{mM}$ IBMX after alkaline dephosphorylation. Control without TMA preincubation is shown. Lines represent exponential fits. Each data point represents the mean \pm SD of three experiments based on duplicates.

of $58 \mathrm{mM}$ extracellular $\mathrm{K}^{+}$concentration $\left(\left[\mathrm{K}^{+}\right]_{\mathrm{ex}}\right)$, the resactevoked hyperpolarization was abolished along with changes in $\mathrm{pH}_{\mathrm{i}}$ and $\mathrm{Ca}^{2+}$ (Fig. 6, A-C), yet the extent of dephosphorylation was largely unaffected (Fig. $6 \mathrm{D})$. At $100 \mathrm{mM}\left[\mathrm{K}^{+}\right]_{\mathrm{ex}}$, resact evoked a slight depolarization ( $15 \mathrm{mV}$; Fig. $6 \mathrm{~A})$, and voltagedependent $\mathrm{Ca}^{2+}$ channels opened, which caused a moderate $\left[\mathrm{Ca}^{2+}\right]_{\mathrm{i}}$ increase (Fig. $6 \mathrm{C}$ ). At $\left[\mathrm{K}^{+}\right]_{\mathrm{ex}} \geq 58 \mathrm{mM}$, dephosphorylation proceeded two to three times slower (Fig. $6 \mathrm{E}$ ), and consequently, cGMP synthesis lasted longer; thereby, cGMP levels were enhanced two- to threefold (Fig. 6 F; Harumi et al., 1992). However, higher cGMP levels did not affect the extent of dephosphorylation (Fig. $6 \mathrm{D}$ ). Thus, the rapid dephosphorylation is independent of resact-induced $\Delta \mathrm{V}_{\mathrm{m}}, \Delta \mathrm{pH}_{\mathrm{i}}, \Delta\left[\mathrm{Ca}^{2+}\right]_{\mathrm{i}}$, and $\Delta \mathrm{cGMP}$.

Finally, three powerful inhibitors of generic phosphatasescalyculin A, okadaic acid (Ishihara et al., 1989), and sanguinarine chloride (Aburai et al., 2010)_did not affect the extent and speed of dephosphorylation (Fig. 6, G and H). Moreover, the resact-induced cGMP increase was not altered by calyculin A (Fig. S4). Thus, inhibitors of PP1, PP2A, and PP2C, which account for the majority of conventional serine/threonine phosphatases, have little or no effect. Collectively, these results suggest that activated GC undergoes autodephosphorylation rather than dephosphorylation by an exogenous phosphatase.

\section{Discussion}

Here, we identify several features of a chemoreceptor that enable sperm to count chemoattractant molecules with a precision at the physical limit and a sampling rate of $\sim 1 \mathrm{~Hz}$. Key to this remarkable skill is (a) a high receptor GC density, (b) a high ligand affinity combined with a wide operational range, (c) a relatively long-lived receptor-ligand complex, and (d) rapid inactivation by multiple autodephosphorylation. We will discuss the functional significance of each feature.

\section{Why is the receptor density so high?}

Chemoattractants randomly impinging on the cell surface cause "molecule noise" that limits the precision of chemical sensing. A measure of the precision of sensing is the uncertainty $\delta c / c$, i.e., the incremental increase $\delta c$ of a concentration $c$; only if $\delta c / c$ is sufficiently high, a new binding event can be distinguished from molecule noise. If we consider a sperm cell as an absorbing sphere covered with surface receptors, the uncertainty $\delta c / c$ of measuring a concentration $c$ is given by $\delta c / c=\left(N_{\mathrm{R}} s D c \tau\right)^{-1 / 2}$, wherein $N_{\mathrm{R}}$ is the number of the receptors, $s$ is the effective radius of the binding site, $D$ is the diffusion constant of the chemoattractant, and $\tau$ is the sampling time (Berg and Purcell, 1977). We calculated $\delta c / c$ for different resact concentrations from $0.1 \mathrm{pM}$ to $10 \mathrm{nM}$ (Fig. $7 \mathrm{~A}$ ) using the following parameters: $N_{\mathrm{R}}=3 \times 10^{5}$ receptors (Table 1 ), $D_{\text {resact }}=2.4 \times 10^{-6} \mathrm{~cm}^{2} / \mathrm{s}$ (Kashikar et al., 2012), and $\tau=0.5 \mathrm{~s}$ (Kaupp et al., 2003; Kashikar et al., 2012). The dimension $s$ of the binding site is not known. Therefore, we used as upper and lower limits the radius of the extracellular GC domain $(2.65 \mathrm{~nm})$ or the radius of the resact peptide $(0.65 \mathrm{~nm}$; Fig. $7 \mathrm{~B})$, respectively. At $1 \mathrm{pM}$ resact, the uncertainty $\delta c / c$ to count molecules is $0.13-0.27$ or 13-27\%. For an ellipsoid-shaped flagellum (half-axis a $=25 \mu \mathrm{m}$ and $b=0.125 \mu \mathrm{m}$; Berg, 1993), at $1 \mathrm{pM}$, on average, 3.5 resact 

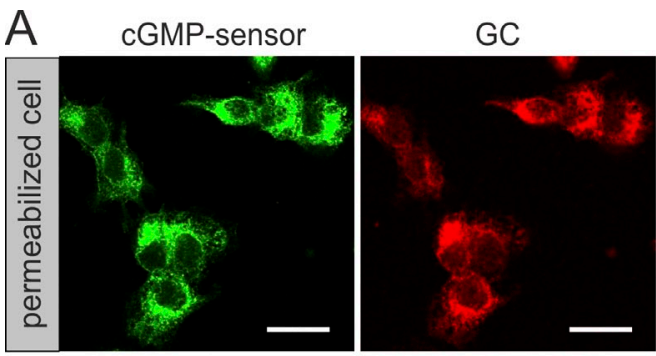

B
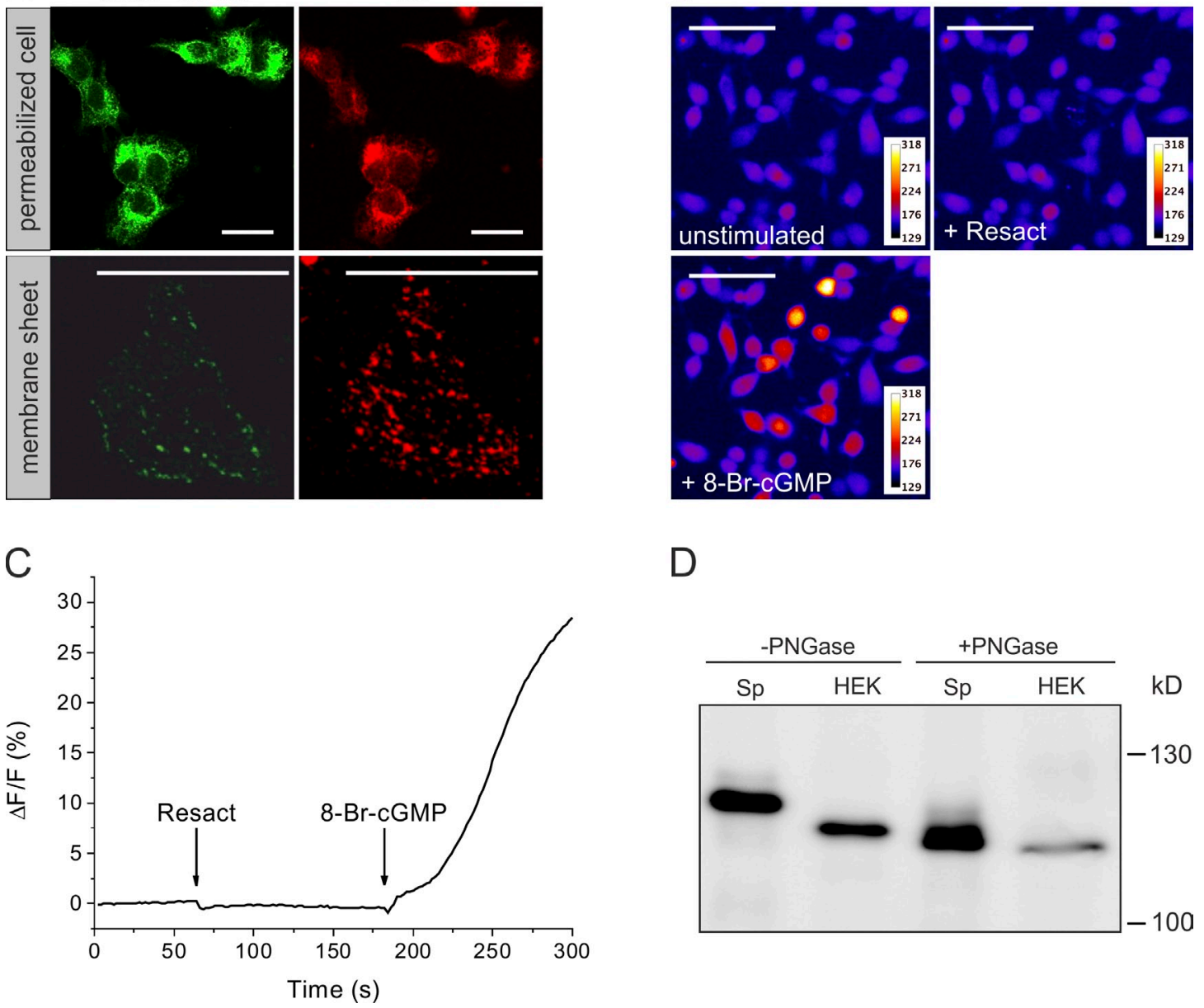

Figure 5. The recombinant GC is catalytically inactive. (A) Immunocytochemical staining of cells (top) or membrane sheets (bottom) of a cell line expressing a cGMP sensor (green) and GC (red). Bars, 20 mm. (B) Fluorescence images taken during a $\mathrm{Ca}^{2+}$ imaging experiment. Transfected HEK293 cells were loaded with Fluo-4-AM and incubated with $200 \mu$ M IBMX for $10 \mathrm{~min}$. Cells were stimulated with $200 \mu \mathrm{M}$ resact and subsequently with $3 \mathrm{mM} 8-\mathrm{Br}-\mathrm{cGMP}$. The increase of $\left[\mathrm{Ca}^{2+}\right]_{i}$ is shown in false colors. Bars, $50 \mathrm{\mu m}$. (C) Mean change in fluorescence $(\Delta \mathrm{F})$ for the experiment (19 cells) shown in B. The addition of $200 \mu \mathrm{M}$ resact and $3 \mathrm{mM} 8$ 8-Br-cGMP is indicated by arrows. (D) Membrane proteins of sea urchin sperm (Sp) after resact stimulation and of the doublestable cell line were analyzed by "dirty" SDS-PAGE (-PNGase). To compare the phosphorylation state of the native and recombinant GC, both were deglycosylated by PNGase. After deglycosylation (+PNGase), the molecular mass of recombinant GC and dephosphorylated GC from sea urchin sperm are almost identical. The molecular masses of two protein size markers are shown on the right.

molecules are impinging during the sampling time of $0.5 \mathrm{~s}$. This exercise illustrates that, at very low resact concentrations, A. punctulata sperm in fact can count individual binding events, i.e., operate at the physical limit. In comparison, bacteria and amoebae operate at nano- to micromolar chemoattractant concentrations; therefore, these cells get by with $\sim 15,000$ receptors per cell (Li and Hazelbauer, 2004; Cannistraro et al., 2011; Sourjik and Wingreen, 2012).

The high GC density is beneficial for a second reason. In the Berg-Purcell model, receptors can be reused within a few milliseconds after clearance of the binding site from ligands. Clearance occurs by dissociation of the ligand from the binding site. This assumption is well reasoned for bacterial receptors with micro- to millimolar affinities and, therefore, dwell times of the ligand on the receptor in the micro- to millisecond range. However, the high ligand affinity of the GC in the subnanomolar range prevents receptors from becoming cleared quickly; consequently, on their voyage to the egg, sperm would suffer a continuous loss of vacant or functional receptors. A high receptor density combined with an extended binding range ensures that a sufficient number of vacant receptors are available even at high ligand concentrations prevailing near the egg. For example, when only $3 \%$ of vacant receptors are left $\left(N_{\mathrm{R}}=9,000\right)$, a resact concentration of $10 \mathrm{nM}$ near the egg (Kashikar et al., 2012) can be sensed with an uncertainty of only $5 \%$ (Fig. 7 A). As much as sperm are single-use machines, the GC is a singleuse chemoreceptor.

Receptor occupancy controls ligand affinity The binding curve of resact is much shallower than a normal binding isotherm and spans six orders of magnitude; thereby, sperm escape premature saturation at higher ligand concentrations. We also provide evidence that ligand affinity is higher at low compared with high chemoattractant concentrations. The subnanomolar affinity at very low concentrations is advantageous in two respects. It provides a ligand-receptor complex 

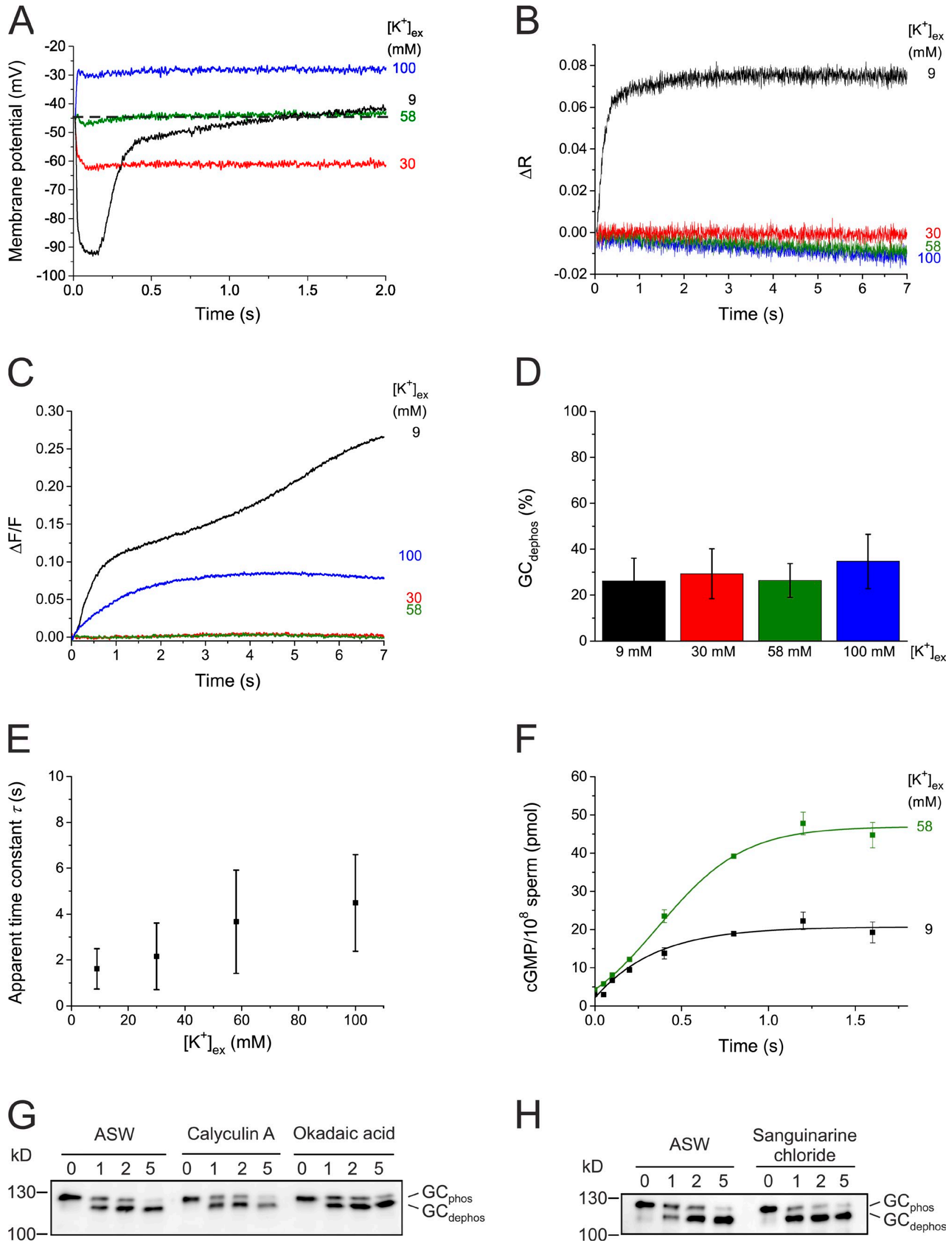

Figure 6. Dephosphorylation is independent of signaling events downstream of GC. (A-F) Signaling events after stimulation with $25 \mathrm{nM}$ resact at different extracellular $\mathrm{K}^{+}$concentrations $\left(\left[\mathrm{K}^{+}\right]_{\mathrm{ex}}\right)$. Each trace represents the mean of at least three recordings. $(\mathrm{A})$ Changes in $V_{m}$ detected by di-8-ANEPPS. The dashed line indicates the resting potential. (B) Changes in $\mathrm{pH}_{\mathrm{i}}$ detected by BCECF. $\triangle \mathrm{R}$ represents the ratio of fluorescence at 540 and $494 \mathrm{~nm}$; excitation 
Figure 7. Limiting accuracy of molecule detection. (A) Uncertainty $\delta c / c$ for the detection of resact versus the receptor number $N_{R}$ for different resact concentrations. Because known, the radii of the globular extracellular domain and of the ligand were used as an upper and lower estimate, respectively. (B) The resact structure was modeled using PEP-FOLD 2012) with a disulfide bridge between $C 1$ and C8. The model was visualized using RasTop, a tool based on RasMol 2.7. (C) Schematic distribution of a GC and CNGK on the flagellum. The scheme depicts the intracellular site of the flagellar membrane. An active GC dimer is depicted in red, an inactive GC dimer is shown in gray, CNGK is depicted in green, and the gradient of cGMP concentration is given in shades of magenta. The GC and CNGK densities are shown to scale. The GC dimer/CNGK ratio is 10:1. the effective radius $s$ of the binding site is not (Maupetit et al., 2009, 2010; Thévenet et al.
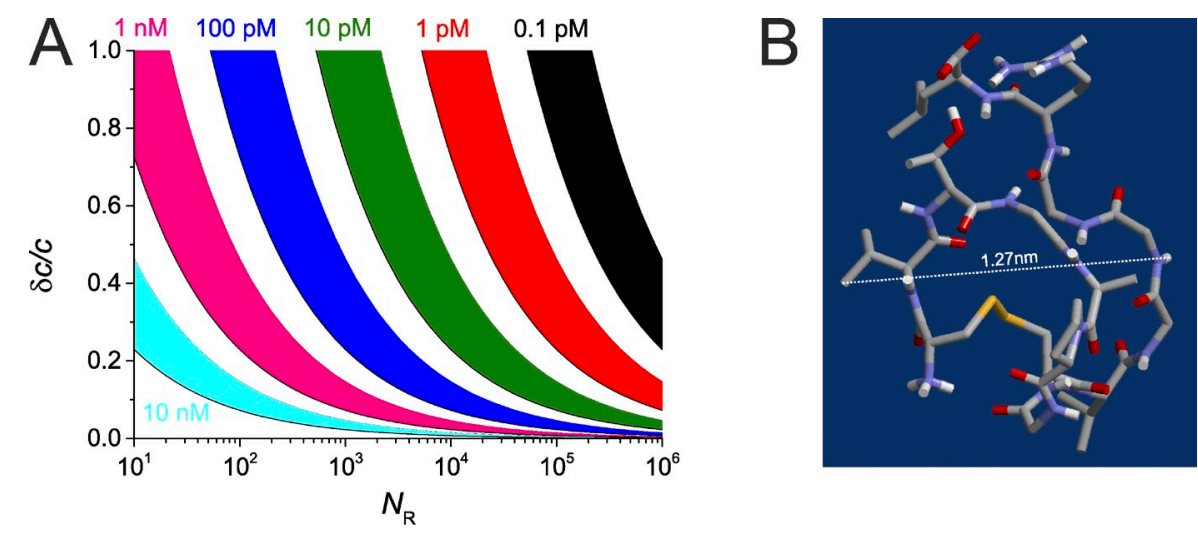

\section{C}

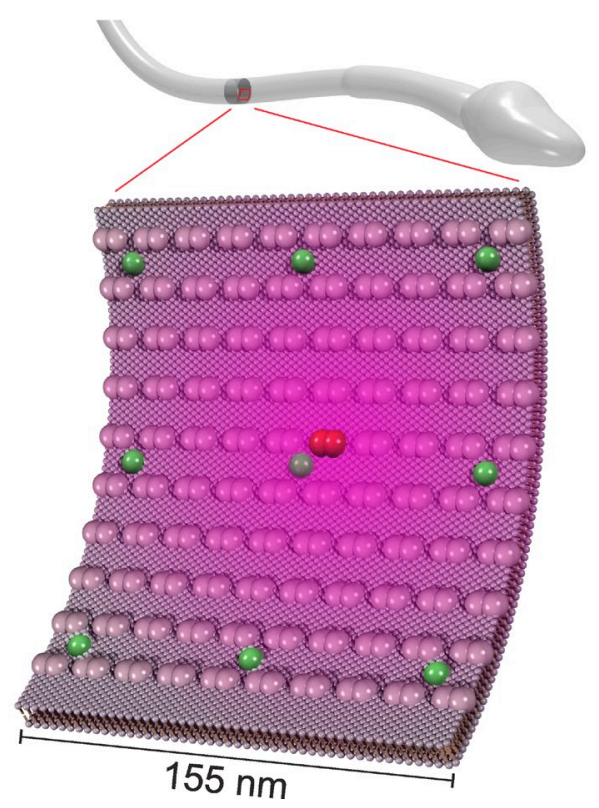

that is relatively long-lived to produce sufficient cGMP molecules, and it prevents overcounting by multiple rebinding of ligand to the same or neighboring receptors, which adds noise without providing new information on the gradient (Endres and Wingreen, 2009).

Negative cooperativity between binding sites might be a mechanism that gradually lowers binding affinity as more receptors become occupied. In fact, a Hill coefficient of $n=0.5$ is consistent with negative cooperativity between subunits in a dimeric or trimeric GC complex. However, other mechanisms cannot be excluded. A set of low- to high-affinity receptors would also extend the operational range. An example of shallow binding isotherms as a result of mixed receptor populations has been provided for CNG channel activation by cGMP (Ruiz et al.,
1999). Alternatively, one of the resact-induced cellular responses could serve as negative feedback that lowers receptor affinity. Any of these mechanisms reconciles a wide dynamic range with the need for high affinity and long signaling lifetime at very low chemoattractant concentrations.

\section{The GC inactivates by autodephosphorylation}

The GC is a moonlighting enzyme, whose multiple catalytic functions are not yet fully appreciated. In fact, members of the GC family in plants have long been known as kinases, whereas their ability to synthesize cGMP was revealed only recently (Irving et al., 2012). Moreover, the GC in rod photoreceptors can undergo

is at $425 \mathrm{~nm}$. (C) Changes in $\left[\mathrm{Ca}^{2+}\right]_{\mathrm{i}}$ detected by Fluo-4. (D) Percentage of dephosphorylated GC after 3 min of stimulation with $25 \mathrm{nM}$ resact at different $\left[\mathrm{K}^{+}\right]_{\mathrm{ex}}$. (E) Apparent time constant $\tau$ of dephosphorylation at $\left[\mathrm{K}^{+}\right]_{\mathrm{ex}}$. (F) Changes in cGMP concentration after resact stimulation at 9 and $58 \mathrm{mM}\left[\mathrm{K}^{+}\right]_{\mathrm{ex}}$ in the presence of $2 \mathrm{mM}$ IBMX. Lines represent exponential fits. D-F represent the means \pm SD of six experiments based on duplicates. (G) Resact-induced dephosphorylation in ASW or with additional $1 \mu \mathrm{M}$ calyculin A or $1 \mu \mathrm{M}$ okadaic acid. (H) Resact-induced dephosphorylation in ASW or with additional $10 \mu \mathrm{M}$ sanguinarine chloride. In $\mathrm{G}$ and $\mathrm{H}$, the amount of $\mathrm{GC}$ was adjusted to $120 \mathrm{nM}$, and sperm were stimulated with $250 \mathrm{nM}$ resact in the presence or absence of the respective phosphatase inhibitors. Time after resact stimulation (seconds) is indicated above the respective lanes. The molecular masses of two protein size markers are shown on the left. 
autophosphorylation and sustains phosphorylation of standard substrates (Aparicio and Applebury, 1996; Bereta et al., 2010).

Here, we add a new twist. Several lines of evidence suggest that the GC inactivates by autodephosphorylation. First, inactivation kinetics is largely independent of the number of occupied GC molecules. This finding is difficult to reconcile with exogenous phosphatase activity: the GC is the most abundant protein in the flagellum, and the availability of a phosphatase should become rate limiting at high stimulation levels. Second, dephosphorylation along with cGMP synthesis is the first detectable cellular event and does not require changes in cGMP, $V_{\mathrm{m}}, \mathrm{pH}_{\mathrm{i}}$, and $\left[\mathrm{Ca}^{2+}\right]_{\mathrm{i}}$. Finally, several inhibitors that abolish the activity of most generic serine/threonine phosphatases are unable to prevent dephosphorylation. However, we cannot exclude the possibility that the GC also displays intrinsic kinase activity in the resting state. Upon resact binding, kinase activity might be diminished and might result in dephosphorylation, i.e., the balance between autokinase and autophosphatase activity determines the phosphorylation status.

Quite generally, phosphorylation/dephosphorylation represents a reversible chemical reaction. Several bifunctional proteins, e.g., the isocitrate dehydrogenase kinase/phosphatase, support both phosphorylation and dephosphorylation (Zheng and Jia, 2010). Most likely, phosphatase and kinase activity of the GC are located in the KHD. Three amino acid motifs (VAIK, HRD, and DFG) are essential for the alignment of ATP and substrate in the active center of classic kinases to facilitate transfer of a phosphogroup (Hanks and Hunter, 1995). In the GC of sea urchin sperm, 26 of 31 amino acid residues that constitute the core structure in kinases are conserved, among them the invariant K597 of the VAIK motif and D710 of the DFG motif. However, the catalytic aspartate in the HRD motif, which initiates phosphotransfer by nucleophilic attack of a hydroxyl group in the substrate, is replaced by a histidine (H691). Pseudokinases lacking one of these key residues have been considered as catalytically inactive, although some pseudokinases developed alternative mechanism for catalysis (Boudeau et al., 2006; Mukherjee et al., 2008). One such example is GC-E of photoreceptors, which displays kinase activity, although it lacks the catalytic aspartate in the HRD motif (Aparicio and Applebury, 1996).

The activity of mammalian receptors GC-A and GC-B is also regulated by phosphorylation; dephosphorylation of five to six serine or threonine residues in the KHD terminates GC activity (Fig. S2 B; Potter and Hunter, 1998a,b; Potter, 2011). Moreover, substitution of serine with glutamate residues, which mimic phosphorylated sites but cannot be dephosphorylated, produces mutants that do not desensitize (Potter and Hunter, 1999; Yoder et al., 2010, 2012). The kinases and phosphatases acting on GC-A and GC-B are not known. We suggest that autophosphorylation/dephosphorylation should also be considered for other members of the GC family.

\section{Why autodephosphorylation in} multiple steps?

Sperm navigation relies on the timing and waveform of $\mathrm{Ca}^{2+}$ signals that control steering responses (Friedrich and Jülicher, 2007; Alvarez et al., 2012, 2014). Sperm periodically sample chemoattractant concentrations for $0.2-0.6 \mathrm{~s}$ about once every second (Kashikar et al., 2012). Thus, the GC inactivation time of $150 \mathrm{~ms}$ is perfectly tuned to the sampling time and frequency. Autodephosphorylation could provide a mechanism for inherently precise timing of inactivation and endows sperm with the ability to track periodic signals with a frequency of $\sim 1 \mathrm{~Hz}$.

However, in the single-molecule regimen, an exponential probability distribution of the $\mathrm{GC}^{*}$ lifetime would produce highly variable $\mathrm{Ca}^{2+}$ responses. This source of molecule noise compromises the precision of chemoattractant measurement at low chemoattractant concentrations. Sequential multistage dephosphorylation could tightly control the GC* lifetime and, thereby, produce uniform $\mathrm{Ca}^{2+}$ responses. A precedent for stepwise receptor inactivation has been proposed for rod photoreceptors (Burns and Pugh, 2010): two phosphorylation steps of rhodopsin and final "capping" of phosphorylated rhodopsin by arrestin are sufficient to control the lifetime of active rhodopsin and, thereby, reduce photon noise (Whitlock and Lamb, 1999; Doan et al., 2006; Burns and Pugh, 2010). However, other mechanisms, such as spatiotemporal filtering by longitudinal diffusion of cGMP, also can produce uniform single-photon responses (Bisegna et al., 2008; Caruso et al., 2011).

Comparison with other signaling systemscommonalities and differences

Several mechanisms have been proposed that explain cellular ultrasensitivity. These concepts largely originate from the study of signaling in photoreceptors, olfactory neurons, and bacteria. Mechanisms include (a) lattices of highly cooperative chemoreceptors in bacteria (Maddock and Shapiro, 1993; Bray et al., 1998; Duke and Bray, 1999; Gestwicki and Kiessling, 2002; Sourjik and Berg, 2004), (b) high multistage gain provided by a cascade of enzymatic reactions in photoreceptors (Pugh and Lamb, 2000; Yau and Hardie, 2009; Kaupp, 2010), (c) local signaling by supramolecular complexes (transducisome or signalosome; Huber et al., 1996; Tsunoda et al., 1997; Scott and Zuker, 1998), and (d) restricted diffusion of chemical messengers in confined cellular subcompartments (Rich et al., 2000, 2001).

Sperm use different principles to achieve single-molecule sensitivity. First, sperm do not rely on arrays of receptor clusters that display positive cooperativity. Second, amplification at the receptor level is orders of magnitude lower in sperm compared with rod photoreceptors. Capture of a single photon initiates the hydrolysis of $\sim 6,600$ cGMP molecules by two-stage amplification (Pugh and Lamb, 2000; Burns and Pugh, 2010), whereas binding of a single resact molecule produces $\sim 11$ cGMP molecules; thus, cGMP amplification in rods is $\sim 600$-fold larger. Nonetheless, rod and sperm operate at a similar level of sensitivity: Binding of a molecule to sperm or capture of a photon by rods each evokes a $\Delta V_{\mathrm{m}}$ of 1-2 $\mathrm{mV}$ (Pugh and Lamb, 2000; Strünker et al., 2006). Taking into account a volume ratio $V_{\text {rod }} / V_{\text {flagellum }}$ of $80 / 2 \mathrm{fl}=40: 1$, the change in cGMP concentration per unit volume is only $15 \times$ larger in rods compared with sperm. Finally, the input resistance of sperm ( $25 \mathrm{G} \Omega$; Navarro et al., 2007; Zeng et al., 2013) is at least fivefold higher than that of mammalian rod photoreceptors (1-2 G 2 ; Schneeweis and Schnapf, 1995); thus, by changing the open probability of 
only a few CNGK channels, sperm can produce a single-molecule response.

Third, it has been argued that second-messenger concentrations steeply decay from the site of synthesis (Rich et al., 2000, 2001), which calls either for a signaling complex between receptors and downstream targets or for restricted diffusion in subcellular compartments that channel the messenger to the target. In order for a GC-CNGK complex to be effective, receptor (GC) and target (CNGK channel) ought to be present stoichiometrically, whereas, in fact, the GC is $\sim 20$-fold more abundant than the CNGK.

To examine the impact of diffusion, we analytically solved unrestricted diffusion of cGMP from a point source of synthesis at the membrane for a cylindrical geometry (see Materials and methods). Within $\sim 15 \mu$ s, the cGMP concentration equilibrates across the flagellar diameter, and within $\sim 100 \mathrm{~ms}$, it equilibrates along the length of the flagellum (Video 1). In a 155-nmlong segment of the flagellum, neglecting cGMP binding to high-affinity buffers or hydrolysis by phosphodiesterase, the cGMP transiently rises to micromolar concentrations that saturate any nearby $\mathrm{CNGK}$ channels $\left(K_{1 / 2}=25 \mathrm{nM}\right.$; Video 1 ; Bönigk et al., 2009). For a regular arrangement of $\sim 100$ GC dimers in a $155 \times 155-\mathrm{nm}$ membrane patch, an active $\mathrm{GC}^{*}$ would be girded by nine CNGK channels at a distance not farther than $\sim 100 \mathrm{~nm}$ (Fig. $7 \mathrm{C}$ ); these next neighbors would be first served with cGMP molecules. Because of the high input resistance of sperm, opening a few CNGK channels is sufficient to hyperpolarize sperm by $2 \mathrm{mV}$ (Strünker et al., 2006). Thus, there is no need to invoke signaling complexes or restricted diffusion to account for single-molecule sensitivity of sperm. The exquisite cGMP sensitivity of CNGK channels, the miniscule flagellar volume, and the high input resistance are key. The hallmarks of this signaling mechanism provide a blueprint for chemical sensing in small compartments, such as olfactory cilia, insect antennae, or even synaptic boutons.

\section{Materials and methods}

\section{Materials and reagents}

We obtained dry sperm by injecting $0.5 \mathrm{M} \mathrm{KCl}$ into the body cavity of A. punctulata or stimulating the animal electrically. Dry sperm was diluted in artificial sea water (ASW), which contained $423 \mathrm{mM} \mathrm{NaCl}, 9.27 \mathrm{mM}$ $\mathrm{CaCl}_{2}, 9 \mathrm{mM} \mathrm{KCl}, 22.94 \mathrm{mM} \mathrm{MgCl} 2,25.5 \mathrm{mM} \mathrm{MgSO}_{4}, 0.1 \mathrm{mM}$ EDTA, and $10 \mathrm{mM}$ Hepes, $\mathrm{pH} 7.8$, adjusted with $\mathrm{NaOH}$. All reagents were purchased from Sigma-Aldrich if not otherwise stated.

\section{Sperm counting}

The number of sperm cells in a sample is critical for the determination of the GC density. Sperm cells in a suspension were counted with a Neubaver cell counter and a CASY Cell Counter system (Roche). Cell counts obtained by either method were not statistically different. The sperm number ranged from $0.7 \times 10^{10}$ to $8.7 \times 10^{10}$ sperm cells/milliliter dry sperm; the mean was $3.4 \pm 1.8 \times 10^{10}$ cells/milliliter (19 animals; Fig. S5).

\section{Cloning of the GC}

An oligo-dT-primed cDNA library was constructed in a phage $\lambda$ ZAP ॥ vector (Agilent Technologies) using poly $(\mathrm{A})^{+}$RNA from $A$. punctulata testis. Approximately 500,000 independent recombinants were screened with a PCR fragment encoding a portion of the KHD of the GC (Singh et al., 1988). A full-length clone of $\sim 4,000$ bp was completely sequenced on both strands. The largest open reading frame codes for a protein of 1,122 amino acid residues with a calculated molecular mass of $126 \mathrm{kD}$. The sequence was analyzed with PROSITE for potential sites of posttranslational modification. For GC expression, the sequence has been cloned into the pcDNA3.1(+)-hygromycin vector (Invitrogen). To ensure proper membrane targeting, the GC signal peptide (amino acids 1-24) has been replaced with the signal peptide of the human epidermal growth factor receptor (MRPSGTAGAALLALLAALCPA).

\section{Antibodies}

Rat monoclonal antibody GCN-3D12 was directed against aa 86-197 in the $\mathrm{N}$-terminal domain of the GC from $A$. punctulata. A fusion protein comprising an N-terminal maltose-binding protein and aa 86-197 of the GC was generated and heterologously expressed in Escherichia coli. After purification with an amylose affinity column (New England Biolabs, Inc.), rats were immunized subcutaneously and intraperitoneally with the fusion protein in the presence of Freund's adjuvant. A boost without adjuvant was given $6 \mathrm{wk}$ after the primary injection. Fusion was performed using standard procedures. Supernatants were tested by differential ELISA with the GC-maltosebinding protein fusion protein and with unrelated proteins coupled to the same carrier. Monoclonal antibodies that reacted specifically with GC were further analyzed by Western blotting. Tissue culture supernatant of clone $3 \mathrm{D} 12$, rat $\lg \mathrm{G} 1$ subclass, was used in this study. The antibody recognized the recombinant and the native protein both in the phosphorylated and unphosphorylated states. Mouse monoclonal antibody CRO/CBL 3B10-121 directed against aa 482-664 of the rat CNGA2 channel was generated following the same procedure (Meyer et al., 2000).

\section{Stable expression of the recombinant GC}

To functionally study the recombinant GC, a HEK293 cell line expressing a mutated olfactory CNGA2 channel was used. The T537S mutation renders the CNG channel more sensitive for CGMP; the mutant channel is suitable as a cGMP sensor in functional assays (Altenhofen et al., 1991). Cells were transfected using the Neon Transfection System (Life Technologies) according to the manufacturer's instructions. For the selection of HEK293 cells stably expressing the CNGA2 mutant and GC, $0.8 \mathrm{mg} / \mathrm{ml}$ antibiotic G418 (Invitrogen) and $0.5 \mathrm{mg} / \mathrm{ml}$ hygromycin B were used. Monoclonal cell lines were identified by Western blotting and immunocytochemistry using CNGA2- and GC-specific antibodies.

\section{Immunocytochemistry and membrane sheets}

Double-stable HEK293 cells were placed on 13-mm coverslips coated with $0.1 \mathrm{mg} / \mathrm{ml}$ poly--Llysine. Cells were cultured at $29^{\circ} \mathrm{C}$ overnight to enhance membrane insertion of the GC. Membrane sheets were produced according to Heuser (2000), applying a 0.1-s ultrasound pulse to cells bathed in $1 \mathrm{ml}$ stabilization buffer $(70 \mathrm{mM} \mathrm{KCl}, 5 \mathrm{mM} \mathrm{MgCl} 2,3 \mathrm{mM} \mathrm{EGTA}, 1 \mathrm{mM} \mathrm{DTT}$, and $30 \mathrm{mM}$ Hepes, pH 7.4). Cells or membrane sheets were fixed for $5 \mathrm{~min}$ with $4 \%$ paraformaldehyde. After permeabilization with $0.5 \%$ Triton X-100 and $5 \%$ ChemiBLOCKER (EMD Millipore), cells or membrane sheets were incubated with primary antibodies CRO/CBL 3B10-121 (1:100) and GCN$3 D 12(1: 10)$ for $1 \mathrm{~h}$. For visualization, goat anti-mouse Alexa Fluor 488 (Life Technologies)- and donkey anti-rat Cy3 (Jackson ImmunoResearch Laboratories, Inc.)- conjugated secondary antibodies were used.

\section{$\mathrm{Ca}^{2+}$ imaging of a double-stable HEK293 cell line}

HEK293 cells stably expressing the recombinant GC and the cGMP sensor were placed in poly--lysine-coated 96-well plates. After culturing at $29^{\circ} \mathrm{C}$ overnight, the medium was replaced by extracellular solution $(140 \mathrm{mM} \mathrm{NaCl}$, $5.4 \mathrm{mM} \mathrm{KCl}, 1 \mathrm{mM} \mathrm{MgCl}$, $1.8 \mathrm{mM} \mathrm{CaCl}_{2}$, and $5 \mathrm{mM} \mathrm{Hepes,} \mathrm{pH} \mathrm{7.4).} \mathrm{Cells}$ were loaded with Fluo-4 acetoxymethylester (AM) in the presence of $0.01 \%$ Pluronic F127 for $1 \mathrm{~h}$. After replacing the loading solution with extracellular solution, changes in fluorescence upon stimulation with $200 \mu \mathrm{M}$ resact or $3 \mathrm{mM} 8$ 8-Br-cGMP were recorded with a cell^R imaging system (Olympus).

\section{Deglycosylation of membrane proteins}

For deglycosylation, membrane proteins were denatured by incubation in $0.5 \% \mathrm{SDS}$ and $40 \mathrm{mM} \mathrm{DTT}$ at $95^{\circ} \mathrm{C}$ for $10 \mathrm{~min}$. Deglycosylation was performed by $500 \mathrm{U}$ PNGase F (New England Biolabs, Inc.) for $2 \mathrm{~h}$ at $37^{\circ} \mathrm{C}$ in the presence of $1 \%$ Nonidet P-40 in $50 \mathrm{mM}$ phosphate buffer, $\mathrm{pH} 7.5$.

\section{Purification of recombinant GC}

As a standard for absolute quantification of the GC, the isotope-labeled protein was heterologously produced in Spodoptera frugiperda (Sf21) cells that were adapted to an IML406 medium supplemented with ${ }^{13} \mathrm{C}_{6}$-lysine, ${ }^{15} \mathrm{~N}_{4}$-arginine, and 5\% FCS (Brüggert et al., 2003). Cells were infected with a baculovirus containing the GC sequence (Bac-to-Bac Baculovirus Expression System; Life Technologies) and harvested after $72 \mathrm{~h}$ by centrifugation $\left(700 \mathrm{~g}\right.$ for $5 \mathrm{~min}$ at $\left.4^{\circ} \mathrm{C}\right)$. The cell pellet was suspended 
into SDS sample buffer $150 \mathrm{mM}$ Tris- $\mathrm{HCl}$, pH 6.8, 2\% SDS, $10 \%$ glycerol, $1 \% \beta$-mercaptoethanol, and $0.02 \%$ bromophenol blue). Proteins were separated by a $6 \%$ SDS-PAGE. The gel band corresponding to the recombinant $\mathrm{GC}$ was excised and eluted by overnight incubation at $4^{\circ} \mathrm{C}$ in a buffer containing $150 \mathrm{mM} \mathrm{NaCl}, 0.1 \%$ SDS, $2 \mathrm{mM} \mathrm{EDTA}$, and $10 \mathrm{mM}$ Tris- $\mathrm{HCl}, \mathrm{pH}$ 8.0. Protein purity was checked on a Coomassie-stained gel. Protein concentration was determined at $280 \mathrm{~nm}\left(\varepsilon_{280}=161,810 \mathrm{M}^{-1} \mathrm{~cm}^{-1}\right.$ and by amino acid analysis (Protagen Protein Services). Incorporation of the label into the recombinant GC was analyzed by selected reactionmonitoring (SRM) MS. The incorporation rate was calculated based on the relative intensity of the unlabeled compared with the fully labeled protein. The purified, labeled GC was used as a PSAQ by MS (Brun et al., 2007).

\section{Mass spectrometric identification of receptor GC}

We analyzed membrane proteins of sperm flagella with MudPIT (Multidimensional Protein Identification Technology). Membrane pellets (300 pg protein) were washed twice with $100 \mathrm{mM}\left(\mathrm{NH}_{4}\right)_{2} \mathrm{CO}_{3}, \mathrm{pH} 11$; proteins were digested by sequencing-grade modified trypsin (Promega) in a methanol and $\mathrm{NH}_{4} \mathrm{HCO}_{3}$ buffer (Blonder et al., 2004). After removal of membranes by centrifugation $\left(100,000 \mathrm{~g}\right.$ for $30 \mathrm{~min}$ at $\left.4^{\circ} \mathrm{C}\right)$, supernatants were desalted using solid-phase extraction pipette tips (Spec PT C18 AR; Varian). For the MudPIT analysis (Fränzel et al., 2010), a mass spectrometer (LTQ Orbitrap Velos; Thermo Fisher Scientific) was used. All database searches were performed using the SEQUEST algorithm, embedded in Proteome Discoverer (version 1.2.0.208; Thermo Fisher Scientific), with an NCBI protein database for Strongylocentrotus purpuratus proteins. The $S$. purpuratus protein sequences for the $G C$ and the potassium-selective channel CNGK were replaced by the respective sequences from $A$. punctulata. Only tryptic peptides with a maximum of two missed cleavage sites were considered. Oxidized methionine was also accepted as modification. The mass tolerance for precursor ions was set to $6 \mathrm{ppm}$; the mass tolerance for peptide fragments was set to $0.8 \mathrm{amu}$. For search result filtering, the false discovery rate was set to $<1 \%$; at least two unique peptides per protein with search result rank 1 were required for identification.

\section{Determination of GC phosphorylation sites}

Phosphorylated amino acid residues of GC were identified by MS. To prepare $\mathrm{GC}_{\text {phos, }}$ dry sperm was solubilized for $30 \mathrm{~min}$ at $4^{\circ} \mathrm{C}$ in a buffer containing $25 \mathrm{mM}$ MES, pH 6.2, 38\% (vol/vol) glycerol, $10 \mathrm{mM} \mathrm{NaF}$, $10 \mathrm{mM}$ benzamidine, phosphatase inhibitor cocktails I and II (SigmaAldrich), and 1\% (vol/vol) Triton X-100. After centrifugation $116,000 \mathrm{~g}$ for $30 \mathrm{~min}$ at $4^{\circ} \mathrm{C}$ ), solubilized proteins were subjected to SDS-PAGE. To prepare $G C_{\text {dephos, }}$ dry sperm was diluted 1:6 in ASW and incubated with $4 \mu \mathrm{M}$ resact for $10 \mathrm{~min}$ at room temperature. Sperm were solubilized in a buffer containing $25 \mathrm{mM} M E S, \mathrm{pH} 6.2$, protease inhibitor cocktail (Roche), and 1\% (vol/vol) Triton X-100. Coomassie-stained protein bands of $\mathrm{GC}_{\text {phos }}$ and $\mathrm{GC}_{\text {dephos }}$ were excised from the gel and further investigated by MS. In-gel digestion with trypsin, chymotrypsin, AspN, and elastase was performed overnight as described in Czupalla et al. (2003) and Schlosser et al. (2005). Titanium dioxide-based enrichment of phosphorylated sequences followed by nano-liquid chromatography (LC)-MS/MS was performed on a mass spectrometer (quadrupole time-of-flight [Q-TOF] Ultima; Micromass) as described in Klemm et al. (2006). Peptides were separated using a capillary column $(3 \mu \mathrm{m}, 100 \AA$, and $150-\mathrm{mm} \times 75-\mu \mathrm{m}$ inner diameter; PepMap C18; Dionex) and a flow rate of $200 \mathrm{nl} / \mathrm{min}$. Mobile phase A was $0.1 \%$ formic acid in acetonitrile-water $3: 97$, $\mathrm{vol} / \mathrm{vol})$, and $B$ was $0.1 \%$ formic acid in acetonitrile-water $(8: 2$, vol/vol). Runs were performed using a gradient of $10-65 \%$ B in $60 \mathrm{~min}$. To perform MS/MS experiments, automatic function switching (survey scanning) was used.

To identify phosphorylated and nonphosphorylated peptides after resact stimulation in semiquantitative terms, we performed additional MS analyses without titanium dioxide-based enrichment of phosphorylated sequences (hybrid mass spectrometer [Orbitrap Elite; Thermo Fisher Scientific] equipped with a liquid chromatography system [UltiMate 3000 LC; Dionex]). MS data were acquired in a data-dependent strategy, selecting MS/MS fragmentation events based on the precursor abundance in the MS scan. LTQ Orbitrap Velos MS/MS spectra were acquired with a target value of 10,000 ions. The maximum injection time for MS/MS was $80 \mathrm{ms,}$ and the dynamic exclusion time was $60 \mathrm{~s}$. Mascot Server 1.9 and 2.2.2 (Matrix Science) were used for database searching of the Q-TOF Ultima and Orbitrap Elite measurements, respectively. For Q-TOF data, mass tolerance was set to $\pm 150 \mathrm{ppm}$ and $\pm 0.15 \mathrm{D}$ for precursor mass and fragment ion mass, respectively. For Orbitrap Elite data, mass tolerance was set to $\pm 10 \mathrm{ppm}$ and $\pm 0.35 \mathrm{D}$ for precursor mass and fragment ion mass, respectively. The site-specific percentage of phosphorylation after stimulation by resact was estimated by evaluation of ion intensity ratios of the corresponding peptide/phosphopeptide pairs as previously described (Boehm et al., 2012).

Searches were performed only on the GC sequence, allowing for either up to three missed cleavages for the tryptic digest or up to four missed cleavages for the digestion with AspN and chymotrypsin. For all searches, the following variable modifications were considered: carboxyamidomethyl for cysteine, propionamide for cysteine, oxidation of methionine, and phosphorylation of serine, threonine, and tyrosine. The search provided a peak list that contained all potentially phosphorylated peptides matching the GC sequence. The processed MS/MS spectra were compared with the theoretical fragment mass of GC peptides.

\section{Quantification of GC density by SRM MS}

14 suitable peptides were identified from MudPIT data with Skyline software (version 1.3.0.3871; MacCoss Lab, University of Washington; Maclean et al., 2010). Based on SRM measurements, the three best peptides (SVLIVTGEPVLR, QQIFATIGTYR, and LGGYELEER) were selected for absolute GC quantification; the corresponding isotope-labeled AQUA peptides (SpikeTides_TQL) were purchased from JPT Peptide Technologies. As internal standards, both the GC-PSAQ and the respective AQUA peptides were used. For quantification of the CNGK channel, the following peptides were used: GIDQSNLFR, AQIYTVAEER, and FVLNPDSPVVR. An aliquot of $5 \times 10^{7}$ sperm was spiked with GC-PSAQ (1.2 $\mu \mathrm{g}$ or 9.53 pmol) and subjected to $12.5 \%$ SDS-PAGE. The sample was allowed to migrate into the separation gel by $\sim 1 \mathrm{~cm}$. The Coomassie-stained gel band was excised and digested overnight at $37^{\circ} \mathrm{C}$ with $6.25 \mathrm{ng} / \mu \mathrm{l}$ trypsin in $25 \mathrm{mM}$ $\mathrm{NH}_{4} \mathrm{HCO}_{3}, \mathrm{pH} 8.6$ (Schluesener et al., 2005). For quantification with AQUA peptides, samples were spiked with 4,000 fmol of each GC and $200 \mathrm{fmol}$ of each CNGK AQUA peptide before tryptic digestion. SRM measurements on a mass spectrometer (TSQ Vantage; Thermo Fisher Scientific) and data analysis with Skyline software were as previously described with some modifications (Wolff et al., 2013). TSQ Vantage was operated by instrument method files of Xcalibur (version 2.1.0.1139; Thermo Fisher Scientific), and for compound optimization, the TSQ Tune software was used (Thermo Fisher Scientific). The SRM instrument method consisted of a list of timed SRM scan events over a 66-min run time, whereby a measuring time window of \pm 1.5 min from each peak maximum was set. Fixed parameters were a resolution of 0.2 full width at half-maximum quadrupole 1 and 0.7 full width at half-maximum quadrupole 3,2 s cycle time, 1.5 mTorr collision gas pressure, and $270^{\circ} \mathrm{C}$ capillary temperature. Chromatography was performed via a trap column (5-um particle, $180 \mu \mathrm{m} \times 20 \mathrm{~mm}$; 2G-V/M Symmetry $\mathrm{C18}$; Waters) and an analytical column (1.8- $\mathrm{\mu m}$ particle; $75 \mu \mathrm{m} \times 150 \mathrm{~mm}$; HSS T3; Waters). Flow rate was $0.4 \mu \mathrm{l} / \mathrm{min}$, and spray voltage was set to 1.6-1.8 kV. The multistep gradient of buffer A $(0.1 \% \mathrm{vol} / \mathrm{vol}$ formic acid) and buffer B $(0.1 \% \mathrm{vol} / \mathrm{vol}$ formic acid in acetonitrile) was established as follows: for $0-6 \mathrm{~min}, 99 \%$ buffer $A$ and $1 \%$ buffer $\mathrm{B}$; for 6-10 $\mathrm{min}, 99-95 \% \mathrm{~A}$; for $10-45 \mathrm{~min}, 95-70 \% \mathrm{~A}$; for $45-51$ $\min ; 70-15 \% \mathrm{~A}$; and for $51-66 \mathrm{~min}, 99 \% \mathrm{~A}$.

\section{Densitometric quantification of GC content}

Sperm number in a sample was adjusted to $10^{7}, 5 \times 10^{6}$, and $2.5 \times 10^{6}$. Sperm samples were dissolved in SDS sample buffer. Proteins were separated by $6 \%$ SDS-PAGE. For calibration, two standard proteins ( $\alpha$-macroglobulin and phosphorylase b) and recombinant GC were run on the same gel at different amounts (100-500 ng). The gel was stained with blue silver (Candiano et al., 2004) overnight and scanned using an imaging system (LAS-3000 Luminescent Image Analyzer; Fujifilm). Intensity of protein bands was densitometrically analyzed with ImageJ software (National Institutes of Health).

\section{Assay of resact binding}

The binding of resact to intact sperm was determined by a bioassay. As described in Kashikar et al. (2012), sperm were incubated for $5 \mathrm{~min}$ at room temperature in LoBind Eppendorf tubes with various concentrations of total resact $\left(R_{t}\right)$; for low concentrations of GC and resact, the incubation time was $\leq 30 \mathrm{~min}$. Nonbound (free) and bound resact $\left(R_{\mathrm{f}}\right.$ and $R_{\mathrm{b}}$, respectively) were separated by centrifugation ( $2 \mathrm{~min}$ at $16,000 \mathrm{~g}$ ). The concentration of free resact $R_{\mathrm{f}}$ in the supernatant was determined by stopped-flow experiments using sperm that had been loaded with the $\mathrm{Ca}^{2+}$ indicator Fluo-4 as the $\mathrm{Ca}^{2+}$ sensor. The initial slope of a $\mathrm{Ca}^{2+}$ signal, evoked by the unknown concentration of free resact $\left(R_{f}\right)$, was measured and compared with the resact standards. Resact standards and samples were appropriately diluted such that standards and samples contained similar resact concentrations around $10 \mathrm{pM}$; calibration is most accurate at $\leq 20 \mathrm{pM}$ resact. This 
calibration assay was performed for each binding experiment. The bound resact concentration was calculated according to $R_{\mathrm{b}}=R_{\mathrm{f}}-R_{\mathrm{f}}$. Total resact concentrations ranged from $\sim 3 \mathrm{pM}$ to $1 \mu \mathrm{M}$. The amount of $G C$ was adjusted accordingly by using different sperm dilutions $\left(1.5 \times 10^{4}\right.$ to $1.8 \times$ $10^{8} \mathrm{sperm} / \mathrm{ml}$.

\section{Determination of dephosphorylation kinetics}

The time course of GC dephosphorylation was analyzed by quenchedflow measurements as described in Kaupp et al. (2003). Sperm density was adjusted to a GC content of $120 \mathrm{nM}$. After stimulation of sperm with different resact concentrations, the reaction was rapidly stopped by mixing with $1.5 \mathrm{M} \mathrm{HClO}_{4}$ in a ratio of $1: 3$. The solution was neutralized by adding fivefold volume of neutralization buffer $(125 \mathrm{mM}$ sodium citrate, $175 \mathrm{mM}$ sodium phosphate, and $250 \mathrm{mM}$ Hepes, $\mathrm{pH} 7.6)$. The phosphorylated $\left(G C_{\text {phos }}\right)$ and dephosphorylated forms of $G C\left(G C_{\text {dephos }}\right)$ were resolved on a $7.5 \%$ dirty SDS-PAGE with $0.13 \%$ bis-acrylamide content and low purity SDS (Sigma-Aldrich; Ward and Vacquier, 1983; Suzuki et al., 1984). GC was visualized by Western blotting using a GC-specific antibody and an HRP-coupled secondary antibody. Western blots were scanned using LAS-3000 Luminescent Image Analyzer. The ratio between $\mathrm{GC}_{\text {phos }}$ and $\mathrm{GC}_{\text {dephos }}$ was densitometrically determined with ImageJ software.

\section{Determination of cGMP synthesis}

Samples obtained by the quenched-flow technique were used for the analysis of cGMP synthesis as well. The solution was neutralized by adding $1 \mathrm{MK}_{3} \mathrm{PO}_{4}$. $\mathrm{KClO}_{4}$ precipitate and cell debris were removed by centrifugation $15 \mathrm{~min}$ at $20,000 \mathrm{~g}$ and $4^{\circ} \mathrm{C}$ ). The cGMP concentration in $40 \mu \mathrm{l}$ of the supernatant was determined using an assay (CatchPoint Cyclic-AMP Fluorescent Assay Kit; Molecular Devices) according to the manufacturer's instructions. To improve the sensitivity of the assay, the supernatant was acetylated with $120 \mu \mathrm{M}$ acetic anhydride and $200 \mu \mathrm{M}$ triethylamine. Alternatively, cGMP content was determined by radioimmune assay (Kaupp et al., 2003)

\section{Determination of GC activity and inactivation}

GC activity was investigated in situ in intact motile sperm. Quenched-flow experiments were performed to obtain dose-response curves of the time course of cGMP levels in sperm stimulated with various resact concentrations. Experiments were performed in the presence of IBMX (final concentration of $1 \mathrm{mM}$ ) to prevent hydrolysis of cGMP by phosphodiesterases. The increase in cGMP was plotted versus stimulation time. The cGMP increase corresponded to the cGMP level of stimulated sperm (mean of triplicates) subtracted by the cGMP level of unstimulated sperm (mean of triplicates). To determine the GC turnover, we had to consider that at short quenching times, the bimolecular binding reaction of resact to $G C$ is not completed. Therefore, we calculated the number of activated GC molecules $\left(G C^{*}\right)$ versus time by using the analytical solution of the bimolecular binding reaction:

$$
\begin{gathered}
\mathrm{GC}^{*}(t)=-\frac{\lambda_{1}\left(e^{\left(\lambda_{1}-\lambda_{2}\right) t}-1\right)}{k_{\text {on }}\left(e^{\left(\lambda_{1}-\lambda_{2}\right) t}-\frac{\lambda_{1}}{\lambda_{2}}\right)} \text {, with } \\
\lambda_{1,2}=-\frac{1}{2}\left(k_{\text {on }}\left[G C_{0}\right]+k_{\text {on }}\left[R_{0}\right]+k_{\text {off }}\right) \pm \\
\frac{1}{2} \sqrt{\left(k_{\text {on }}\left[G_{0}\right]+k_{\text {on }}\left[R_{0}\right]+k_{\text {off }}\right)^{2}-4 k_{\text {on }}^{2}\left[G C_{0}\right]\left[R_{0}\right]} .
\end{gathered}
$$

[GC $\left.C_{0}\right]$ is the total $G C$ concentration; $\left[R_{0}\right]$ is the total resact concentration; $k_{\text {on }}$ and $k_{\text {off }}$ are the forward and backward rates of the binding reaction, respectively. We assumed $k_{\text {on }}=5 \times 10^{7} \mathrm{M}^{-1} \mathrm{~s}^{-1}$; because of the high affinity of the GC for resact, $k_{\text {off }}$ is very small and was neglected for the calculations performed. To determine the mean number of activated GC molecules from the time course of GC production we used

$$
\overline{G C^{*}}(t)=\frac{1}{t} \int_{0}^{t} G C^{*}(t) d t
$$

The apparent turnover number of $G C\left(T_{\text {app }}\right)$ is determined by

$$
T_{\text {app }}=\frac{[\mathrm{cGMP}](t)}{\overline{G C^{*}}(t)} \text {. }
$$

An inactivation model is fitted to the time course of $T_{\text {app }}$ :

$$
T_{\text {app }}=T \exp \left(-k_{i} t\right)+y_{0}
$$

with $T$, the turnover number, and $k_{i}$, the inactivation rate.

Values of $T$ and $k_{\mathrm{i}}$ were determined for each resact concentration independently (3-10 experiments; Fig. $3 \mathrm{D}$ and E). We calculated the arithmetic mean of these values to obtain $T$ and $k_{i}$ as given in the Results.

\section{Numerical analysis of kinetic data}

Numerical analysis was performed using the program DynaFit (3.28.064; BioKin, Ltd.). DynaFit derives the equations for the numerical analysis directly from reaction schemes. The following reaction scheme was used:

$$
\left[G C_{\text {phos }}\right]+[\mathrm{L}] \underset{k_{-1}}{\stackrel{k_{1}}{\rightleftarrows}}\left[\mathrm{GC}_{\text {phos }} \mathrm{L}\right] \stackrel{k_{2}}{\longrightarrow}\left[\mathrm{GC}_{\text {dephos }} \mathrm{L}\right] \underset{k_{-3}}{\stackrel{k_{3}}{\rightleftarrows}}[\mathrm{GC} \text { dephos }]+[\mathrm{L}]
$$

Input data were the mean values of the time course of dephosphorylation (mean of 6-12 experiments for each concentration). We used $k_{1}=k_{3}=$ $2 \times 10^{8} \mathrm{M}^{-1} \mathrm{~s}^{-1}$ as a fixed parameter. The following results were obtained: $k_{-1}=294 \pm 220 \mathrm{~s}^{-1}, k_{2}=7.53 \pm 4.6 \mathrm{~s}^{-1}$, and $k_{-3}=2.5 \pm 1.9 \mathrm{~s}^{-1}$. An offset of $9.4 \pm 1.1 \mathrm{nM}$ was obtained, indicating that the reaction ceases.

\section{Diffusion of cGMP in the flagellum}

Diffusion of cGMP along the flagellum is modeled by solving the diffusion equation:

$$
\frac{\partial c(\mathbf{r}, t)}{\partial t}=D \Delta c(\mathbf{r}, t)
$$

for a closed cylinder of radius $a$ and length $L$. In Eq. 5, $c(\mathbf{r}, t)$ is the cGMP concentration as a function of the position $\mathbf{r}$ and time $t, D$ is the diffusion coefficient, and $\Delta$ denotes the three-dimensional Laplace operator. The GC is located at the cell surface. It is furthermore assumed that at time 0 , a single cGMP molecule exists at the position of the GC. Eq. 5 can be solved in cylindrical coordinates by an expansion into orthogonal functions (Morse and Feshbach, 1953), and the final solution reads

$$
c(\rho, \phi, z, t)=\sqrt{\frac{\pi}{D t}} \sum_{n=-\infty}^{\infty} \sum_{\alpha=1}^{\infty} c_{n, \alpha} J_{n}\left(k_{n, \alpha} \rho\right) \exp \left[\text { in } \phi-D k_{n, \alpha}^{2} t-\frac{z^{2}}{4 D t}\right],
$$

in which $(\rho, \varphi, z)$ are cylindrical coordinates. The site of cGMP production (GC position) is located at $(\rho=a, \varphi=0, z=0)$, and the flagellum extends between $z=-L / 2$ and $z=L / 2$. The functions $J_{n}$ denote Bessel functions of the first kind (Abramowitz and Stegum, 1984). The $k_{n, \alpha}$ are the roots of the transcendental equation

$$
J_{n}^{\prime}\left(k_{n, \alpha} a\right)=0,
$$

in which a prime denotes the first derivative, and $\alpha$ indexes the different roots. The constants $c_{n, \alpha}$ are given by

$$
c_{n, \alpha}(q)=\left[2 \pi^{2}\left(a^{2}-\frac{n^{2}}{k_{n, \alpha}^{2}}\right) J_{n}\left(k_{n, \alpha} a\right)\right]^{-1} .
$$

The equilibration of the cGMP concentration across the flagellum is governed by the smallest nonzero root $k_{n, \alpha}$ which has the value $k_{0,2}=$ $\sim 3.8317 / \alpha\left(k_{0,1}\right.$ being 0$)$. The characteristic relaxation time connected with this root is $\left(k_{0,2}^{2} D\right)^{-1}$, and for a flagellar radius $a$ of $150 \mathrm{~nm}$ and a cGMP diffusion coefficient of $\sim 10^{-6} \mathrm{~cm}^{2} / \mathrm{s}$, a characteristic time of $\sim 15 \mu \mathrm{s}$ is obtained. Thus, any inhomogeneity of cGMP concentration across the flagellum is rapidly equilibrated.

Measurement of changes in $V_{m} \mathrm{Ca}^{2+}{ }_{i}$, and $\mathrm{pH}$ in sperm

We studied resact-induced changes in $\mathrm{V}_{\mathrm{m}},\left[\mathrm{Ca}^{2+}\right]_{i}$, and $\mathrm{pH}_{\mathrm{i}}$ with a rapidmixing device (SFM-400; Biologic) in the stopped-flow mode. The changes in $V_{m},\left[\mathrm{Ca}^{2+}\right]_{i}$, and $\mathrm{pH}_{\mathrm{i}}$ were measured with the fluorescent dyes di-8-ANEPPS, 
Fluo-4-AM, and BCECF-AM (Molecular Probes), respectively (Kaupp et al., 2003; Strünker et al., 2006).

\section{Statistics}

Values are given as means \pm SD unless otherwise stated. Goodness of regressions is given as \pm standard error of the regression.

\section{Online supplemental material}

Fig. S1 shows the densitometric analysis of a representative Coomassiestained SDS polyacrylamide gel to estimate the GC density per sperm cell. Fig. S2 shows the primary structure of the GC. Fig. S3 shows changes in $\mathrm{pH}_{\mathrm{i}}$ of sperm stimulated with either resact, $\mathrm{NH}_{4} \mathrm{Cl}$, or TMA. Fig. $\mathrm{S} 4$ shows that the resact-induced cGMP increase is not altered by the phosphatase inhibitor calyculin. Fig. S5 shows the statistics of sperm counting. Table S1 shows turnover values of the GC reported in the literature. Table S2 shows phosphopeptides of the phosphorylated GC identified by nano-LC-MS/MS. Table S3 shows tryptic peptides of the dephosphorylated GC. Video 1 shows the simulated cGMP diffusion along the sperm flagellum. Online supplemental material is available at $h \mathrm{htp}: / / \mathrm{www}$.jcb .org/cgi/content/full/jcb.201402027/DC1.

We thank Heike Krause for preparing the manuscript, Dr. René Pascal for graphical work, and Dr. Luis Alvarez for careful reading.

This work was supported by the German Research Foundation and the Fonds der Chemischen Industrie.

The authors declare no competing financial interests.

Submitted: 6 February 2014

Accepted: 15 July 2014

\section{References}

Abramowitz, M., and I.A. Stegum. 1984. Pocketbook of Mathematical Functions. Abridged Edition of "Handbook of Mathematical Functions." M. Danos and J. Rafelski, editors. Verlag Harri Deutsch, Frankfurt, Germany. 468 pp.

Aburai, N., M. Yoshida, M. Ohnishi, and K. Kimura. 2010. Sanguinarine as a potent and specific inhibitor of protein phosphatase $2 \mathrm{C}$ in vitro and induces apoptosis via phosphorylation of p38 in HL60 cells. Biosci. Biotechnol. Biochem. 74:548-552. http://dx.doi.org/10.1271/bbb.90735

Altenhofen, W., J. Ludwig, E. Eismann, W. Kraus, W. Bönigk, and U.B. Kaupp. 1991. Control of ligand specificity in cyclic nucleotidegated channels from rod photoreceptors and olfactory epithelium. Proc. Natl. Acad. Sci. USA. 88:9868-9872. http://dx.doi.org/10.1073/ pnas. 88.21.9868

Alvarez, L., L. Dai, B.M. Friedrich, N.D. Kashikar, I. Gregor, R. Pascal, and U.B. Kaupp. 2012. The rate of change in $\mathrm{Ca}^{2+}$ concentration controls sperm chemotaxis. J. Cell Biol. 196:653-663. http://dx.doi.org/10.1083/jcb .201106096

Alvarez, L., B.M. Friedrich, G. Gompper, and U.B. Kaupp. 2014. The computational sperm cell. Trends Cell Biol. 24:198-207. http://dx.doi.org/ 10.1016/j.tcb.2013.10.004

Aparicio, J.G., and M.L. Applebury. 1996. The photoreceptor guanylate cyclase is an autophosphorylating protein kinase. J. Biol. Chem. 271:2708327089. http://dx.doi.org/10.1074/jbc.271.43.27083

Babcock, D.F., M.M. Bosma, D.E. Battaglia, and A. Darszon. 1992. Early persistent activation of sperm $\mathrm{K}^{+}$channels by the egg peptide speract. Proc. Natl. Acad. Sci. USA. 89:6001-6005. http://dx.doi.org/10.1073/ pnas.89.13.6001

Bereta, G., B. Wang, P.D. Kiser, W. Baehr, G.F. Jang, and K. Palczewski. 2010. A functional kinase homology domain is essential for the activity of photoreceptor guanylate cyclase 1. J. Biol. Chem. 285:1899-1908. http:// dx.doi.org/10.1074/jbc.M109.061713

Berg, H.C. 1993. Random Walks in Biology. Expanded edition. Princeton University Press, Princeton, NJ. 152 pp.

Berg, H.C., and E.M. Purcell. 1977. Physics of chemoreception. Biophys. J. 20:193-219. http://dx.doi.org/10.1016/S0006-3495(77)85544-6

Bhandawat, V., J. Reisert, and K.W. Yau. 2010. Signaling by olfactory receptor neurons near threshold. Proc. Natl. Acad. Sci. USA. 107:18682-18687. http://dx.doi.org/10.1073/pnas.1004571107

Bisegna, P., G. Caruso, D. Andreucci, L. Shen, V.V. Gurevich, H.E. Hamm, and E. DiBenedetto. 2008. Diffusion of the second messengers in the cytoplasm acts as a variability suppressor of the single photon response in vertebrate phototransduction. Biophys. J. 94:3363-3383. http://dx.doi .org/10.1529/biophysj.107.114058
Blonder, J., T.P. Conrads, L.R. Yu, A. Terunuma, G.M. Janini, H.J. Issaq, J.C. Vogel, and T.D. Veenstra. 2004. A detergent- and cyanogen bromide-free method for integral membrane proteomics: application to Halobacterium purple membranes and the human epidermal membrane proteome. Proteomics. 4:31-45. http://dx.doi.org/10.1002/pmic.200300543

Boehm, M.E., J. Seidler, B. Hahn, and W.D. Lehmann. 2012. Site-specific degree of phosphorylation in proteins measured by liquid chromatographyelectrospray mass spectrometry. Proteomics. 12:2167-2178. http://dx.doi .org/10.1002/pmic.201100561

Bönigk, W., A. Loogen, R. Seifert, N. Kashikar, C. Klemm, E. Krause, V. Hagen, E. Kremmer, T. Strünker, and U.B. Kaupp. 2009. An atypical CNG channel activated by a single cGMP molecule controls sperm chemotaxis. Sci. Signal. 2:ra68. http://dx.doi.org/10.1126/scisignal.2000516

Boudeau, J., D. Miranda-Saavedra, G.J. Barton, and D.R. Alessi. 2006. Emerging roles of pseudokinases. Trends Cell Biol. 16:443-452. http://dx.doi .org/10.1016/j.tcb.2006.07.003

Bray, D., M.D. Levin, and C.J. Morton-Firth. 1998. Receptor clustering as a cellular mechanism to control sensitivity. Nature. 393:85-88. http://dx.doi .org/10.1038/30018

Brüggert, M., T. Rehm, S. Shanker, J. Georgescu, and T.A. Holak. 2003. A novel medium for expression of proteins selectively labeled with $15 \mathrm{~N}-$ amino acids in Spodoptera frugiperda (Sf9) insect cells. J. Biomol. NMR. 25:335-348. http://dx.doi.org/10.1023/A:1023062906448

Brun, V., A. Dupuis, A. Adrait, M. Marcellin, D. Thomas, M. Court, F. Vandenesch, and J. Garin. 2007. Isotope-labeled protein standards: toward absolute quantitative proteomics. Mol. Cell. Proteomics. 6:21392149. http://dx.doi.org/10.1074/mcp.M700163-MCP200

Burns, M.E., and E.N. Pugh Jr. 2010. Lessons from photoreceptors: turning off g-protein signaling in living cells. Physiology (Bethesda). 25:72-84. http://dx.doi.org/10.1152/physiol.00001.2010

Candiano, G., M. Bruschi, L. Musante, L. Santucci, G.M. Ghiggeri, B. Carnemolla, P. Orecchia, L. Zardi, and P.G. Righetti. 2004. Blue silver: a very sensitive colloidal Coomassie G-250 staining for proteome analysis. Electrophoresis. 25:1327-1333. http://dx.doi.org/10.1002/ elps.200305844

Cannistraro, V.J., G.D. Glekas, C.V. Rao, and G.W. Ordal. 2011. Cellular stoichiometry of the chemotaxis proteins in Bacillus subtilis. J. Bacteriol. 193:3220-3227. http://dx.doi.org/10.1128/JB.01255-10

Caruso, G., P. Bisegna, D. Andreucci, L. Lenoci, V.V. Gurevich, H.E. Hamm, and E. DiBenedetto. 2011. Identification of key factors that reduce the variability of the single photon response. Proc. Natl. Acad. Sci. USA. 108:7804-7807. http://dx.doi.org/10.1073/pnas.1018960108

Caterina, M.J., P.N. Devreotes, J. Borleis, and D. Hereld. 1995. Agonist-induced loss of ligand binding is correlated with phosphorylation of cAR1, a G protein-coupled chemoattractant receptor from Dictyostelium. J. Biol. Chem. 270:8667-8672. http://dx.doi.org/10.1074/jbc.270.15.8667

Cook, N.J., L.L. Molday, D. Reid, U.B. Kaupp, and R.S. Molday. 1989. The cGMP-gated channel of bovine rod photoreceptors is localized exclusively in the plasma membrane. J. Biol. Chem. 264:6996-6999.

Czupalla, C., B. Nürnberg, and E. Krause. 2003. Analysis of class I phosphoinositide 3-kinase autophosphorylation sites by mass spectrometry. Rapid Commun. Mass Spectrom. 17:690-696. http://dx.doi.org/10.1002/rcm.967

Darszon, A., A. Guerrero, B.E. Galindo, T. Nishigaki, and C.D. Wood. 2008. Sperm-activating peptides in the regulation of ion fluxes, signal transduction and motility. Int. J. Dev. Biol. 52:595-606. http://dx.doi.org/10 .1387/ijdb.072550ad

Doan, T., A. Mendez, P.B. Detwiler, J. Chen, and F. Rieke. 2006. Multiple phosphorylation sites confer reproducibility of the rod's single-photon responses. Science. 313:530-533. http://dx.doi.org/10.1126/science.1126612

Duke, T.A.J., and D. Bray. 1999. Heightened sensitivity of a lattice of membrane receptors. Proc. Natl. Acad. Sci. USA. 96:10104-10108. http://dx.doi .org/10.1073/pnas.96.18.10104

Endres, R.G., and N.S. Wingreen. 2009. Accuracy of direct gradient sensing by cell-surface receptors. Prog. Biophys. Mol. Biol. 100:33-39. http:// dx.doi.org/10.1016/j.pbiomolbio.2009.06.002

Fränzel, B., C. Trötschel, C. Rückert, J. Kalinowski, A. Poetsch, and D.A. Wolters. 2010. Adaptation of Corynebacterium glutamicum to salt-stress conditions. Proteomics. 10:445-457. http://dx.doi.org/10.1002/pmic.200900482

Friedrich, B.M., and F. Jülicher. 2007. Chemotaxis of sperm cells. Proc. Natl. Acad. Sci. USA. 104:13256-13261. http://dx.doi.org/10.1073/pnas.0703530104

Gauss, R., R. Seifert, and U.B. Kaupp. 1998. Molecular identification of a hyperpolarization-activated channel in sea urchin sperm. Nature. 393:583-587. http://dx.doi.org/10.1038/31248

Gerber, S.A., J. Rush, O. Stemman, M.W. Kirschner, and S.P. Gygi. 2003. Absolute quantification of proteins and phosphoproteins from cell lysates by tandem MS. Proc. Natl. Acad. Sci. USA. 100:6940-6945. http://dx.doi .org/10.1073/pnas.0832254100 
Gestwicki, J.E., and L.L. Kiessling. 2002. Inter-receptor communication through arrays of bacterial chemoreceptors. Nature. 415:81-84. http://dx.doi .org/10.1038/415081a

Hallem, E.A., W.C. Spencer, R.D. McWhirter, G. Zeller, S.R. Henz, G. Rätsch, D.M. Miller III, H.R. Horvitz, P.W. Sternberg, and N. Ringstad. 2011. Receptor-type guanylate cyclase is required for carbon dioxide sensation by Caenorhabditis elegans. Proc. Natl. Acad. Sci. USA. 108:254-259. http://dx.doi.org/10.1073/pnas.1017354108

Hanks, S.K., and T. Hunter. 1995. Protein kinases 6. The eukaryotic protein kinase superfamily: kinase (catalytic) domain structure and classification. FASEB J. 9:576-596.

Harumi, T., K. Hoshino, and N. Suzuki. 1992. Effects of sperm-activating peptide I on Hemicentrotus pulcherrimus spermatozoa in high potassium sea water. Dev. Growth Differ. 34:163-172. http://dx.doi.org/10.1111/ j.1440-169X.1992.tb00005.X

Haynes, L.W., A.R. Kay, and K.W. Yau. 1986. Single cyclic GMP-activated channel activity in excised patches of rod outer segment membrane. Nature. 321:66-70. http://dx.doi.org/10.1038/321066a0

Hedgecock, E.M., and R.L. Russell. 1975. Normal and mutant thermotaxis in the nematode Caenorhabditis elegans. Proc. Natl. Acad. Sci. USA. 72:40614065. http://dx.doi.org/10.1073/pnas.72.10.4061

Heuser, J. 2000. The production of 'cell cortices' for light and electron microscopy. Traffic. 1:545-552. http://dx.doi.org/10.1034/j.1600-0854.2000.010704.x

Huber, A., P. Sander, A. Gobert, M. Bähner, R. Hermann, and R. Paulsen. 1996. The transient receptor potential protein (Trp), a putative store-operated $\mathrm{Ca}^{2+}$ channel essential for phosphoinositide-mediated photoreception, forms a signaling complex with NorpA, InaC and InaD. EMBO J. 15:7036-7045.

Irving, H.R., L. Kwezi, J. Wheeler, and C. Gehring. 2012. Moonlighting kinases with guanylate cyclase activity can tune regulatory signal networks. Plant Signal. Behav. 7:201-204. http://dx.doi.org/10.4161/psb.18891

Ishihara, H., B.L. Martin, D.L. Brautigan, H. Karaki, H. Ozaki, Y. Kato, N. Fusetani, S. Watabe, K. Hashimoto, D. Uemura, et al. 1989. Calyculin A and okadaic acid: inhibitors of protein phosphatase activity. Biochem. Biophys. Res. Commun. 159:871-877. http://dx.doi.org/10.1016/0006-291X(89)92189-X

Johnson, C.H., D.L. Clapper, M.M. Winkler, H.C. Lee, and D. Epel. 1983. A volatile inhibitor immobilizes sea urchin sperm in semen by depressing the intracellular pH. Dev. Biol. 98:493-501. http://dx.doi.org/10.1016/ 0012-1606(83)90378-0

Kashikar, N.D., L. Alvarez, R. Seifert, I. Gregor, O. Jäckle, M. Beyermann, E. Krause, and U.B. Kaupp. 2012. Temporal sampling, resetting, and adaptation orchestrate gradient sensing in sperm. J. Cell Biol. 198:1075-1091. http://dx.doi.org/10.1083/jcb.201204024

Kaupp, U.B. 2010. Olfactory signalling in vertebrates and insects: differences and commonalities. Nat. Rev. Neurosci. 11:188-200.

Kaupp, U.B. 2012. 100 years of sperm chemotaxis. J. Gen. Physiol. 140:583586. http://dx.doi.org/10.1085/jgp.201210902

Kaupp, U.B., J. Solzin, E. Hildebrand, J.E. Brown, A. Helbig, V. Hagen, M. Beyermann, F. Pampaloni, and I. Weyand. 2003. The signal flow and motor response controling chemotaxis of sea urchin sperm. Nat. Cell Biol. 5:109-117. http://dx.doi.org/10.1038/ncb915

Klein, P., B. Knox, J. Borleis, and P. Devreotes. 1987. Purification of the surface cAMP receptor in Dictyostelium. J. Biol. Chem. 262:352-357.

Klemm, C., S. Otto, C. Wolf, R.F. Haseloff, M. Beyermann, and E. Krause. 2006. Evaluation of the titanium dioxide approach for MS analysis of phosphopeptides. J. Mass Spectrom. 41:1623-1632. http://dx.doi.org/10 .1002/jms.1129

Koller, K.J., M.T. Lipari, and D.V. Goeddel. 1993. Proper glycosylation and phosphorylation of the type A natriuretic peptide receptor are required for hormone-stimulated guanylyl cyclase activity. J. Biol. Chem. 268:5997-6003.

Leinders-Zufall, T., A.P. Lane, A.C. Puche, W. Ma, M.V. Novotny, M.T. Shipley, and F. Zufall. 2000. Ultrasensitive pheromone detection by mammalian vomeronasal neurons. Nature. 405:792-796. http://dx.doi .org/10.1038/35015572

Leinders-Zufall, T., R.E. Cockerham, S. Michalakis, M. Biel, D.L. Garbers, R.R. Reed, F. Zufall, and S.D. Munger. 2007. Contribution of the receptor guanylyl cyclase GC-D to chemosensory function in the olfactory epithelium. Proc. Natl. Acad. Sci. USA. 104:14507-14512. http://dx.doi .org/10.1073/pnas.0704965104

Li, M., and G.L. Hazelbauer. 2004. Cellular stoichiometry of the components of the chemotaxis signaling complex. J. Bacteriol. 186:3687-3694. http:// dx.doi.org/10.1128/JB.186.12.3687-3694.2004

MacLean, B., D.M. Tomazela, N. Shulman, M. Chambers, G.L. Finney, B. Frewen, R. Kern, D.L. Tabb, D.C. Liebler, and M.J. MacCoss. 2010. Skyline: an open source document editor for creating and analyzing targeted proteomics experiments. Bioinformatics. 26:966-968. http://dx.doi.org/10.1093/ bioinformatics/btq054
Maddock, J.R., and L. Shapiro. 1993. Polar location of the chemoreceptor complex in the Escherichia coli cell. Science. 259:1717-1723. http://dx.doi .org/10.1126/science.8456299

Maupetit, J., P. Derreumaux, and P. Tufféry. 2009. PEP-FOLD: an online resource for de novo peptide structure prediction. Nucleic Acids Res. 37(Suppl. 2):W498-W503. http://dx.doi.org/10.1093/nar/gkp323

Maupetit, J., P. Derreumaux, and P. Tufféry. 2010. A fast method for large-scale de novo peptide and miniprotein structure prediction. J. Comput. Chem. 31:726-738.

Meyer, M.R., A. Angele, E. Kremmer, U.B. Kaupp, and F. Müller. 2000. A cGMPsignaling pathway in a subset of olfactory sensory neurons. Proc. Natl. Acad. Sci. USA. 97:10595-10600. http://dx.doi.org/10.1073/pnas.97.19.10595

Morse, P.M., and H. Feshbach. 1953. Methods of theoretical physics. Part II. McGraw Hill, New York. 1978 pp.

Mukherjee, K., M. Sharma, H. Urlaub, G.P. Bourenkov, R. Jahn, T.C. Südhof, and M.C. Wahl. 2008. CASK Functions as a $\mathrm{Mg}^{2+}$-independent neurexin kinase. Cell. 133:328-339. http://dx.doi.org/10.1016/j.cell.2008.02.036

Müller, D., M. Hildebrand, J. Lübberstedt, M. Kuhn, and R. Middendorff. 2010. The membrane receptors guanylyl cyclase-A and -B undergo distinctive changes in post-translational modification during brain development. J. Neurochem. 115:1024-1034. http://dx.doi.org/10.1111/j.1471 $-4159.2010 .06985 . x$

Munger, S.D., T. Leinders-Zufall, L.M. McDougall, R.E. Cockerham, A. Schmid, P. Wandernoth, G. Wennemuth, M. Biel, F. Zufall, and K.R. Kelliher. 2010. An olfactory subsystem that detects carbon disulfide and mediates food-related social learning. Curr. Biol. 20:1438-1444. http:// dx.doi.org/10.1016/j.cub.2010.06.021

Murayama, T., J. Takayama, M. Fujiwara, and I.N. Maruyama. 2013. Environmental alkalinity sensing mediated by the transmembrane guanylyl cyclase GCY-14 in C. elegans. Curr. Biol. 23:1007-1012. http://dx.doi .org/10.1016/j.cub.2013.04.052

Navarro, B., Y. Kirichok, and D.E. Clapham. 2007. KSper, a pH-sensitive $\mathrm{K}^{+}$ current that controls sperm membrane potential. Proc. Natl. Acad. Sci. USA. 104:7688-7692. http://dx.doi.org/10.1073/pnas.0702018104

Nishigaki, T., and A. Darszon. 2000. Real-time measurements of the interactions between fluorescent speract and its sperm receptor. Dev. Biol. 223:17-26. http://dx.doi.org/10.1006/dbio.2000.9734

Ogawa, H., Y. Qiu, C.M. Ogata, and K.S. Misono. 2004. Crystal structure of hormone-bound atrial natriuretic peptide receptor extracellular domain: rotation mechanism for transmembrane signal transduction. J. Biol. Chem. 279:28625-28631. http://dx.doi.org/10.1074/jbc.M313222200

Peshenko, I.V., E.V. Olshevskaya, A.B. Savchenko, S. Karan, K. Palczewski, W. Baehr, and A.M. Dizhoor. 2011. Enzymatic properties and regulation of the native isozymes of retinal membrane guanylyl cyclase (RetGC) from mouse photoreceptors. Biochemistry. 50:5590-5600. http://dx.doi .org/10.1021/bi200491b

Potter, L.R. 2011. Guanylyl cyclase structure, function and regulation. Cell. Signal. 23:1921-1926. http://dx.doi.org/10.1016/j.cellsig.2011.09.001

Potter, L.R., and T. Hunter. 1998a. Identification and characterization of the major phosphorylation sites of the B-type natriuretic peptide receptor. J. Biol. Chem. 273:15533-15539. http://dx.doi.org/10.1074/jbc.273.25.15533

Potter, L.R., and T. Hunter. 1998b. Phosphorylation of the kinase homology domain is essential for activation of the A-type natriuretic peptide receptor. Mol. Cell. Biol. 18:2164-2172.

Potter, L.R., and T. Hunter. 1999. Identification and characterization of the phosphorylation sites of the guanylyl cyclase-linked natriuretic peptide receptors A and B. Methods. 19:506-520. http://dx.doi.org/10.1006/meth .1999 .0893

Pugh, E.N., Jr., and T.D. Lamb. 2000. Phototransduction in vertebrate rods and cones: Molecular mechanisms of amplification, recovery and light adaptation. In Molecular mechanisms in visual transduction. Handbook of Biological Physics. Vol. 3. D.G. Stavenga, W.J. DeGrip, and E.N. Pugh Jr, editors. Elsevier Science B.V. (North-Holland), Amsterdam. 183-255.

Ramarao, C.S., and D.L. Garbers. 1985. Receptor-mediated regulation of guanylate cyclase activity in spermatozoa. J. Biol. Chem. 260:8390-8396.

Ramot, D., B.L. MacInnis, and M.B. Goodman. 2008. Bidirectional temperaturesensing by a single thermosensory neuron in C. elegans. Nat. Neurosci. 11:908-915. http://dx.doi.org/10.1038/nn.2157

Rich, T.C., K.A. Fagan, H. Nakata, J. Schaack, D.M.F. Cooper, and J.W. Karpen. 2000. Cyclic nucleotide-gated channels colocalize with adenylyl cyclase in regions of restricted cAMP diffusion. J. Gen. Physiol. 116:147-161. http://dx.doi.org/10.1085/jgp.116.2.147

Rich, T.C., T.E. Tse, J.G. Rohan, J. Schaack, and J.W. Karpen. 2001. In vivo assessment of local phosphodiesterase activity using tailored cyclic nucleotide-gated channels as cAMP sensors. J. Gen. Physiol. 118:63-78. http://dx.doi.org/10.1085/jgp.118.1.63 
Ruiz, M., R.L. Brown, Y. He, T.L. Haley, and J.W. Karpen. 1999. The singlechannel dose-response relation is consistently steep for rod cyclic nucleotide-gated channels: implications for the interpretation of macroscopic dose-response relations. Biochemistry. 38:10642-10648. http://dx.doi .org/10.1021/bi990532w

Schlosser, A., J.T. Vanselow, and A. Kramer. 2005. Mapping of phosphorylation sites by a multi-protease approach with specific phosphopeptide enrichment and NanoLC-MS/MS analysis. Anal. Chem. 77:5243-5250. http://dx.doi.org/10.1021/ac050232m

Schluesener, D., F. Fischer, J. Kruip, M. Rögner, and A. Poetsch. 2005. Mapping the membrane proteome of Corynebacterium glutamicum. Proteomics. 5:1317-1330. http://dx.doi.org/10.1002/pmic.200400993

Schneeweis, D.M., and J.L. Schnapf. 1995. Photovoltage of rods and cones in the macaque retina. Science. 268:1053-1056. http://dx.doi.org/10 $.1126 /$ science. 7754386

Schröder-Lang, S., M. Schwärzel, R. Seifert, T. Strünker, S. Kateriya, J. Looser, M. Watanabe, U.B. Kaupp, P. Hegemann, and G. Nagel. 2007. Fast manipulation of cellular cAMP level by light in vivo. Nat. Methods. 4:3942. http://dx.doi.org/10.1038/nmeth975

Scott, K., and C.S. Zuker. 1998. Assembly of the Drosophila phototransduction cascade into a signalling complex shapes elementary responses. Nature. 395:805-808. http://dx.doi.org/10.1038/27448

Shimomura, H., and D.L. Garbers. 1986. Differential effects of resact analogues on sperm respiration rates and cyclic nucleotide concentrations. Biochemistry. 25:3405-3410. http://dx.doi.org/10.1021/bi00359a046

Shimomura, H., L.J. Dangott, and D.L. Garbers. 1986. Covalent coupling of a resact analogue to guanylate cyclase. J. Biol. Chem. 261:15778-15782.

Singh, S., D.G. Lowe, D.S. Thorpe, H. Rodriguez, W.-J. Kuang, L.J. Dangott, M. Chinkers, D.V. Goeddel, and D.L. Garbers. 1988. Membrane guanylate cyclase is a cell-surface receptor with homology to protein kinases. Nature. 334:708-712. http://dx.doi.org/10.1038/334708a0

Sourjik, V., and H.C. Berg. 2004. Functional interactions between receptors in bacterial chemotaxis. Nature. 428:437-441. http://dx.doi.org/10.1038/ nature 02406

Sourjik, V., and N.S. Wingreen. 2012. Responding to chemical gradients: bacterial chemotaxis. Curr. Opin. Cell Biol. 24:262-268. http://dx.doi .org/10.1016/j.ceb.2011.11.008

Strünker, T., I. Weyand, W. Bönigk, Q. Van, A. Loogen, J.E. Brown, N. Kashikar, V. Hagen, E. Krause, and U.B. Kaupp. 2006. A K ${ }^{+}$-selective cGMP-gated ion channel controls chemosensation of sperm. Nat. Cell Biol. 8:1149-1154. http://dx.doi.org/10.1038/ncb1473

Sun, L., H. Wang, J. Hu, J. Han, H. Matsunami, and M. Luo. 2009. Guanylyl cyclase-D in the olfactory $\mathrm{CO}_{2}$ neurons is activated by bicarbonate. Proc. Natl. Acad. Sci. USA. 106:2041-2046. http://dx.doi.org/10.1073/ pnas.0812220106

Suzuki, N., H. Shimomura, E.W. Radany, C.S. Ramarao, G.E. Ward, J.K. Bentley, and D.L. Garbers. 1984. A peptide associated with eggs causes a mobility shift in a major plasma membrane protein of spermatozoa. $J$. Biol. Chem. 259:14874-14879.

Thévenet, P., Y. Shen, J. Maupetit, F. Guyon, P. Derreumaux, and P. Tufféry. 2012. PEP-FOLD: an updated de novo structure prediction server for both linear and disulfide bonded cyclic peptides. Nucleic Acids Res. 40(W1):W288-W293. http://dx.doi.org/10.1093/nar/gks419

Tsunoda, S., J. Sierralta, Y. Sun, R. Bodner, E. Suzuki, A. Becker, M. Socolich, and C.S. Zuker. 1997. A multivalent PDZ-domain protein assembles signalling complexes in a G-protein-coupled cascade. Nature. 388:243-249. http://dx.doi.org/10.1038/40805

Vaandrager, A.B. 2002. Structure and function of the heat-stable enterotoxin receptor/guanylyl cyclase C. Mol. Cell. Biochem. 230:73-83. http:// dx.doi.org/10.1023/A:1014231722696

Vacquier, V.D., and G.W. Moy. 1986. Stoichiometry of phosphate loss from sea urchin sperm guanylate cyclase during fertilization. Biochem. Biophys. Res. Commun. 137:1148-1152. http://dx.doi.org/10.1016/ 0006-291X(86)90345-1

Ward, G.E., and V.D. Vacquier. 1983. Dephosphorylation of a major sperm membrane protein is induced by egg jelly during sea urchin fertilization. Proc. Natl. Acad. Sci. USA. 80:5578-5582. http://dx.doi.org/10.1073/pnas .80.18.5578

Ward, G.E., G.W. Moy, and V.D. Vacquier. 1986. Dephosphorylation of sea urchin sperm guanylate cyclase during fertilization. Adv. Exp. Med. Biol. 207:359-382.

Wedel, B., and D. Garbers. 2001. The guanylyl cyclase family at Y2K. Annu. Rev. Physiol. 63:215-233. http://dx.doi.org/10.1146/annurev.physiol.63.1.215

Whitlock, G.G., and T.D. Lamb. 1999. Variability in the time course of single photon responses from toad rods: termination of rhodopsin's activity. Neuron. 23:337-351. http://dx.doi.org/10.1016/S0896-6273(00)80784-9
Wilson, E.M., and M. Chinkers. 1995. Identification of sequences mediating guanylyl cyclase dimerization. Biochemistry. 34:4696-4701. http://dx doi.org/10.1021/bi00014a025

Wolff, D., F. ter Veld, T. Köhler, and A. Poetsch. 2013. Combined application of targeted and untargeted proteomics identifies distinct metabolic alterations in the tetraacetylphytosphingosine (TAPS) producing yeast Wickerhamomyces ciferrii. J. Proteomics. 82:274-287. http://dx.doi .org/10.1016/j.jprot.2013.03.002

Yau, K.W., and R.C. Hardie. 2009. Phototransduction motifs and variations. Cell. 139:246-264. http://dx.doi.org/10.1016/j.cell.2009.09.029

Yoder, A.R., M.D. Stone, T.J. Griffin, and L.R. Potter. 2010. Mass spectrometric identification of phosphorylation sites in guanylyl cyclase A and B. Biochemistry. 49:10137-10145. http://dx.doi.org/10.1021/bi101700e

Yoder, A.R., J.W. Robinson, D.M. Dickey, J. Andersland, B.A. Rose, M.D. Stone, T.J. Griffin, and L.R. Potter. 2012. A functional screen provides evidence for a conserved, regulatory, juxtamembrane phosphorylation site in guanylyl cyclase a and B. PLOS ONE. 7:e36747. http://dx.doi .org/10.1371/journal.pone.0036747

Yu, H., E. Olshevskaya, T. Duda, K. Seno, F. Hayashi, R.K. Sharma, A.M. Dizhoor, and A. Yamazaki. 1999. Activation of retinal guanylyl cyclase- 1 by $\mathrm{Ca}^{2+}$-binding proteins involves its dimerization. J. Biol. Chem. 274:15547-15555. http://dx.doi.org/10.1074/jbc.274.22.15547

Zeng, X.H., B. Navarro, X.M. Xia, D.E. Clapham, and C.J. Lingle. 2013. Simultaneous knockout of Slo3 and CatSper1 abolishes all alkalizationand voltage-activated current in mouse spermatozoa. J. Gen. Physiol. 142:305-313. http://dx.doi.org/10.1085/jgp.201311011

Zheng, J., and Z. Jia. 2010. Structure of the bifunctional isocitrate dehydrogenase kinase/phosphatase. Nature. 465:961-965. http://dx.doi.org/10 .1038 /nature09088

Zimmerman, A.L., and D.A. Baylor. 1986. Cyclic GMP-sensitive conductance of retinal rods consists of aqueous pores. Nature. 321:70-72. http://dx.doi org/10.1038/321070a0

Zufall, F., and S.D. Munger. 2010. Receptor guanylyl cyclases in mammalian olfactory function. Mol. Cell. Biochem. 334:191-197. http://dx.doi .org/10.1007/s11010-009-0325-9 